Article

\title{
A New Formulation for Predicting the Collision Damage of Steel Stiffened Cylinders Subjected to Dynamic Lateral Mass Impact
}

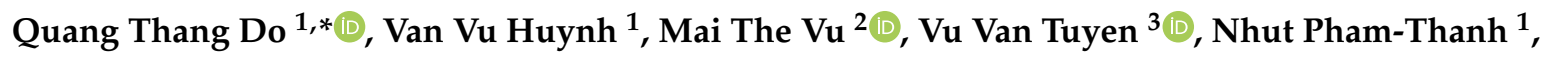 \\ Tran Hung Tra ${ }^{1}$, Quang-Viet Vu ${ }^{4,5}$ and Sang-Rai Cho ${ }^{6,7}$ \\ 1 Department of Naval Architecture and Ocean Engineering, Nha Trang University, 02 Nguyen Dinh Chieu, \\ Nha Trang 650000, Vietnam; vuhv@ntu.edu.vn (V.V.H.); nhutpt@ntu.edu.vn (N.P.-T.); tra@ntu.edu.vn (T.H.T.) \\ 2 School of Intelligent Mechatronics Engineering, Sejong University, 98 Gunja-dong, Gwangjin-gu, \\ Seoul 143-747, Korea; maithevu90@sejong.ac.kr \\ 3 Faculty of Shipbuilding, Vietnam Maritime University, Hai Phong 180000, Vietnam; \\ tuyenvv.dt@vimaru.edu.vn \\ 4 Institute of Research and Development, Duy Tan University, Danang 550000, Vietnam; \\ vietvq@vimaru.edu.vn \\ 5 Faculty of Civil Engineering, Vietnam Maritime University, 484 Lach Tray Street, Le Chan District, \\ Haiphong 180000, Vietnam \\ 6 School of Naval Architecture and Ocean Engineering, University of Ulsan, Ulsan 44610, Korea; \\ srcho@ulsan.ac.kr \\ 7 UlsanLab Inc., Ulsan 44610, Korea \\ * Correspondence: thangdq@ntu.edu.vn; Tel.: +84-903-102-869
}

Received: 1 May 2020; Accepted: 28 May 2020; Published: 1 June 2020

check for updates

\begin{abstract}
The objective of this study is to develop a new formulation for predicting the permanent local denting damage of steel ring and/or stringer-stiffened cylinders under dynamic lateral mass impact. The considered scenarios could represent the collisions of offshore cylindrical structures with bow or stern of service vessels or floating objects. Before deriving the formulations, the numerical methods were developed using ABAQUS/Explicit to determine the deformation of these stiffened cylinder structures subjected to dynamic lateral mass impact. Next, rigorous parametric studies were performed on the actual design full-scaled stiffened cylinder examples using the developed numerical method. Based on the rigorous numerical results, new simple design formulations to predict the maximum permanent local dent depth of a stiffened cylinder are derived through a regression study as the function of a non-dimensional energy parameter. The accuracy and reliability of the derived formulations are confirmed by comparison with the available test results, nonlinear FEA and existing analytical, and empirical equations in the literature. A good agreement with existing test data for ship-offshore structure collisions was achieved.
\end{abstract}

Keywords: stiffened cylinder; collision damage; dynamic mass impact; design formulation

\section{Introduction}

Large diameter steel ring and/or stringer-stiffened cylinders are widely used in marine structures as a major structural component of floating offshore installations, main legs of tension leg platforms, submarine hulls, and spars. Recently, these structures are also applied extensively in floating offshore wind turbine foundations. The major advantages of stiffened cylinders are good axial compressive and external pressure loading, and low drag resistance force by passing fluid.

During operation, stiffened cylindrical members may be potentially damaged caused unexpected loading such as ship collisions (such as tugboats, commercial ships, ferryboats, support vessels, and 
private vessels), groundings, slamming, or the impact of dropped heavy objects. In these accidents, ship collisions have been highlighted as the most significant cause of damage or even catastrophic loss of offshore installations due to loss of structural integrity [1]. A minor collision will result in only repairable local damage to the structure and probably will not call for a stop of operation. However, the major collision will damage cylindrical structures globally, and assuredly require a stop of operations. Therefore, it is a necessity to increase attention on the influences of collision damage on the strength of the structure and serviceability in the initial design step for safety concerns.

To evaluate the internal mechanics of cylindrical structures based on collision events, many approaches are applied such as empirical formulation, simplified analytical method, finite element modeling (FEMs), and experiments. However, it is difficult to perform full-scaled cylindrical collision experiments, and sometimes impossible, because of extremely costly and technological requirements. Thus, small-scale laboratory model tests are the most convincing methods for evaluating the impact resistance of cylindrical structures. There are relatively few studies that provided the experiments on ring and/or stringer-stiffened cylinders subjected to dynamic mass impact. Cerik et al. [2] presented the drop-weight impact test on two fabricated steel ring-stiffened cylinders. The damage was created by using the striking mass with a knife-edge indenter. Ghazijahani et al. [3] provided the experiment on 27 locally dented unstiffened cylinders under compression. The dent imperfections of different depths, locations, and orientations were considered. It was found that the dented area was largely affected by the deformations in the buckling modes and buckling strengths. They also presented the experimental study on 14 thin-walled intact and dented cylindrical shells subjected to external pressure [4], 8 damaged tubular members under bending loads [5], and 6 locally dented conical shell models under axial compression [6]. In general, the ultimate load-carrying capacity of dented structures was strongly decreased when compared with the intact structures.

Recently, Do et al. [7] conducted the dynamic mass impact tests on two stringer-stiffened cylinders (denoted as SS-C-1 and SS-C-2) with local impact at mid-span. The specimens had three bays each, divided by two T-shaped ring-stiffeners and stiffened with 20 stringer-stiffeners in axial direction, respectively. These models were then performed under external hydrostatic pressure to assess the residual strength of these structures after collision [8]. Do et al. [9] provided details of the second series on two ring-stiffened cylinders, namely, RS-C-3 and RS-C-4. These models had seven bays and were separated by six flat-bar ring-stiffeners. The damage was performed by the free-fall testing frame and their residual strengths were checked under external hydrostatic pressure by pressure chamber. In these references, the test results are very valuable for a common understanding of the dynamic impact behaviors of stiffened cylinders. Furthermore, they can be used to validate the numerical analyses or derive the analytical formulations for collision response of stiffened cylinders.

For assessment of local denting of cylindrical shells, only a few analytical studies were provided by Wierzbicki et al. [10-12], Hoo Fatt et al. [13], and Moussouros et al. [14]. They focused on deriving the simplified formulae to predict the quasi-static denting behaviors of stiffened cylinders. Simplified formulae are the most rapid tools for predicting the impact strength of cylinder structures, especially during the initial design stage and the risk assessment. In these studies, the cylindrical shell is assumed as perfectly plastic material and neglected the elastic strains in the damage areas. It is also assumed that the outside of the damage regions is rigid, and that the plastic damage zone is localized and finite. However, in real structural behaviors, the dynamic strain rate effects and inertial forces should be considered for assessing the extent of local denting damage accurately [15]. Furthermore, in these formulations, the force-displacement and deformation profile is not smooth because of sudden jumps in the vicinity of the stiffeners and it does not match well the experimental observations. Because these researches are purely theoretical, they are required to be verified with reliable test data. Detailed explanations of these formulations are given in Section 5 .

More recently, Cerik et al. [2] improved the existing formulations proposed by Hoo Fatt and Wierzbicki [13] for the local denting behavior of ring-stiffened cylinders. He revised the circumferential bending resistance by including the effect of the ring stiffeners and changing the fully plastic bending 
moment of the cylindrical shell by an equivalent bending moment per length. This simple formulation has good accuracy when compared to the limited experimental data. However, more studies are needed to validate this analytical approach with a wide range of geometry and reliable test data. Another approximate formulation to forecast the permanent local denting damage of the ring-stiffener cylinder was reported by Do et al. [9]. These formulations are derived using the FEA results of rigorous case studies on the real design full-scale ring-stiffened cylinders. It has high accuracy when compared with available test models. However, there are several shortcomings existing in these formulations. First, the impact location was considered in these formulations only at mid-bay of the ring-stiffeners and perpendicular to the axial direction. In actual cases, the impact position is varying on the cylinder structures. It is clear that the impact behavior of the stiffened cylinder was sharply improved when impact locations were close to ring stiffener [7]. Thus, the effects of various impact locations need to consider predicting the extent of damage to cylinder structures. Secondly, the damage deformations were only generated by a rigid knife-edge indenter with a rounded tip, but the striking mass in a real case is not only a knife-edge indenter but also a hemispherical or rectangular indenter type. Therefore, to get accuracy of the extent of damage prediction, all the information on striking mass types should be investigated. To overcome these shortcomings, the proposed formulations developed in this study for assessing the permanent local dent depth, include all parameters such as impact location factor, impact angle factor, and indenter shape factor. To the best of the authors' knowledge, until recently, there was no reliable equation or code recommendation for assessing the permanent damage of ringor/and stringer-stiffened cylinders under dynamic mass impact loading. Therefore, it is sorely needed to propose the new formulations to predict the extent of local dent depth of these structures, and this study's objective is to fill that gap.

Nowadays, finite element modeling (FEM) is an excellent tool for predicting ship collisions and groundings. Numerical assessment of cylinder structures under collision loading conditions has been performed by many researchers [16-23]. The nonlinear FEA was also used to perform ship-ship collisions [24-27], validation of the analytical solutions [28,29], and experimental results [30-32]. Furthermore, FEM has the convenience of incorporating full-scale actual structures and all parameters such as material properties (strain hardening and strain rate effects), loadings and boundary conditions, and other structures for both striking ships and offshore structures. Thus, besides the computational economic efficiency, a carefully implemented nonlinear FEA, which is also confirmed with reliable test models, would be the most effective approach of evaluating the collision responses of offshore structures.

In this background, this study aims to derive the new formulations to evaluate the permanent local damage of steel ring- or/and stringer-stiffened cylinders under dynamic lateral mass impact. Based on the regression analysis of the rigorous parametric study results by nonlinear FEA, new empirical formulations were proposed and compared with available test results and existing analytical equations.

\section{Numerical Analysis}

\subsection{Description of Test Data}

In this section, the collision experiments of six stiffened cylinders reported by Cerik et al. [2] and the authors [7-9], among them, four ring-stiffened cylinders and two stringer-stiffened cylinders, are evaluated. All models were performed under dynamic mass impact using the drop-weight impact machine at the Ulsan Lab, University of Ulsan, Ulsan, Korea. The damages were generated by using the striking mass with a knife-edge indenter. The scantlings and material properties of the specimens are shown in Tables 1 and 2. The impact test conditions of the specimens are listed in Table 3. The details of scantlings, experimental setup, and test results are found in the references [2,7-9]. The purpose of using these test results is to further validation with finite element analysis, as well as the accuracy of the proposed closed-form formulations in the next sections. 
Table 1. Measured dimensions of test models.

\begin{tabular}{ccccccc}
\hline Model & RS-C-1 & RS-C-2 & RS-C-3 & RS-C-4 & SS-C-1 & SS-C-2 \\
\hline Radius (mm), $R$ & 400 & 400 & 550 & 550 & 550 & 550 \\
Thickness (mm), $t$ & 3.96 & 3.95 & 4.97 & 4.94 & 2.98 & 2.97 \\
Total length (mm), $L$ & 1060 & 1060 & 1060 & 1060 & 1060 & 1060 \\
Ring-stiffener spacing $(\mathrm{mm}), l$ & 200 & 200 & 150 & 150 & 600 & 600 \\
Number of rings, $n_{r}$ & 6 & 6 & 8 & 8 & 2 & 2 \\
Number of stringers, $n_{r}$ & - & - & - & - & 20 & 20 \\
Ring-stiffener web height $(\mathrm{mm}), h_{r w}$ & 35.0 & 35.0 & 40.0 & 40.0 & 200 & 200 \\
Ring-stiffener web thickness (mm), $t_{r w}$ & 3.94 & 4.0 & 5.81 & 5.81 & 4.90 & 4.92 \\
Stringer-stiffener web height, $h_{s w}$ & - & - & - & - & 65.0 & 65.0 \\
Stringer-stiffener web thickness (mm), $t_{s w}$ & - & - & - & - & 4.98 & 4.87 \\
Ring-stiffener flange width $(\mathrm{mm}), b_{r f}$ & - & - & - & - & 50.0 & 50.0 \\
Ring-stiffener flange thickness $(\mathrm{mm}), t_{r f}$ & - & - & - & - & 4.89 & 4.88 \\
\hline
\end{tabular}

Table 2. Material properties of test models.

\begin{tabular}{ccccccc}
\hline Model & RS-C-1 & RS-C-2 & RS-C-3 & RS-C-4 & SS-C-1 & SS-C-2 \\
\hline Yield strength (MPa), $\sigma_{Y}$ & 302.2 & 309 & 274.9 & 274.9 & 335.9 & 335.9 \\
Ultimate strength (MPa), $\sigma_{T}$ & 396.2 & 397.3 & 370.5 & 370.5 & 417.0 & 417.0 \\
Elasticity modulus (GPa), $E$ & 206.0 & 200.0 & 202.4 & 202.4 & 210.0 & 210.0 \\
Hardening start strain, $\varepsilon_{H S}$ & 0.0227 & 0.0224 & 0.0145 & 0.0145 & 0.0223 & 0.0223 \\
Ultimate tensile strain, $\varepsilon_{T}$ & 0.196 & 0.194 & 0.234 & 0.234 & 0.1727 & 0.1727 \\
Fracture strain, $\varepsilon_{F}$ & 0.376 & 0.366 & 0.427 & 0.427 & 0.3811 & 0.3811 \\
\hline
\end{tabular}

Table 3. Impact test conditions for each model.

\begin{tabular}{ccccccc}
\hline Model & RS-C-1 & RS-C-2 & RS-C-3 & RS-C-4 & SS-C-1 & SS-C-2 \\
\hline Drop height $(\mathrm{mm})$ & 1600 & 1200 & 1200 & 1600 & 1600 & 1580 \\
Collision velocity (m/s) & 5.602 & 4.852 & 4.852 & 5.602 & 5.600 & 5.570 \\
Striker mass (kg) & 295 & 295 & 500 & 500 & 500 & 600 \\
Kinetic energy (J) & 4629 & 3472 & 5249 & 7846 & 7848 & 9300 \\
\hline
\end{tabular}

\subsection{Finite Element Modelling}

Nonlinear finite element analyses were performed by using the explicit solution of the ABAQUS software. The full geometry of the test model was modelled by applying four-node doubly curved shell elements S4R in the ABAQUS library (version 6.14, ABAQUS Inc., Providence, Rhode Island). The Simpson rule was applied with five points of the thickness integration. For the striking mass, it was assumed as a rigid body with a 3-D bilinear rigid quadrilateral element (R3D4). To control the inertial properties and initial impact velocity of the striker, a reference node was attached at the area centroid of the striker's faces. It is noted that the rotations of the striking mass during the impact were also considered in the numerical model.

The optimum mesh size was selected after performing the convergence studies. The mesh size of the contact zone was $5 \times 5 \mathrm{~mm}$, while that of the out of the contact zone was $10 \times 10 \mathrm{~mm}$. This mesh size is sufficiently fine for recording the local denting response precisely. For the boundary conditions, the ends of both thick support structures of the model were restrained in all degrees. The support structures were fully clamped at four bottom bolt holes as the clamped boundary conditions in the experiment. The general contact algorithm with a penalty method was applied for the contact between the striking mass and the cylinder shell surface. The contact friction coefficient is designed by 0.3 to account for the slipping between the surfaces of the indenter and cylindrical shell. The full geometry and boundary conditions of each model are provided in the finite element modelling, as shown in Figure 1. 


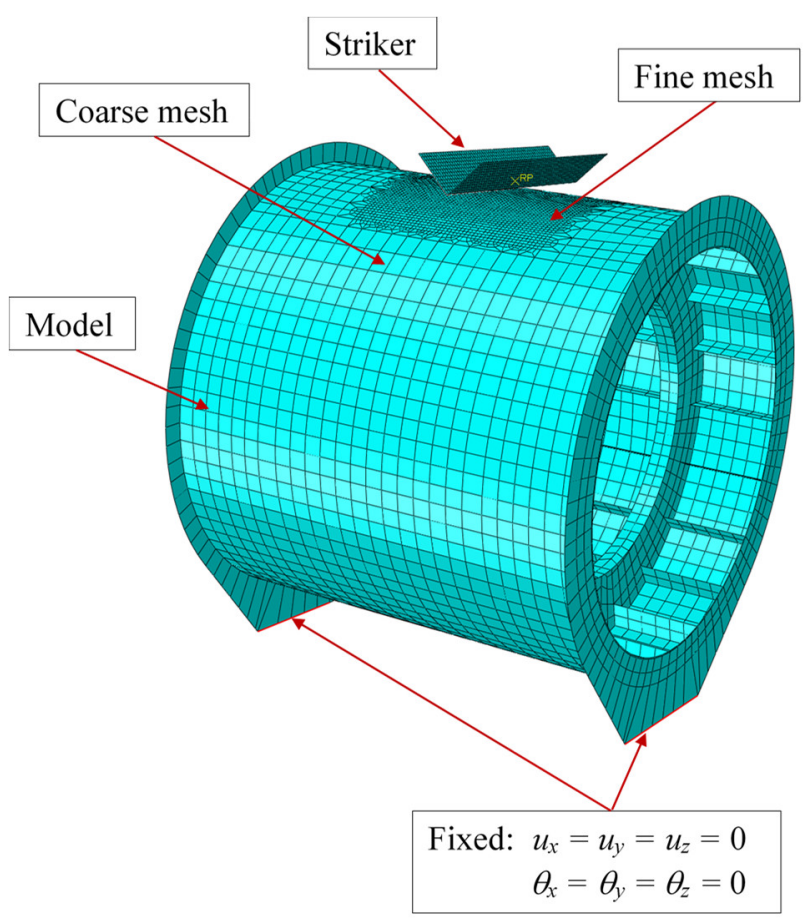

Figure 1. Finite element modelling of the stringer-stiffened cylinder.

Additionally, during the collision test, the model was vibrated elastically. Thus, to reduce the vibrations and to quickly achieve a static equilibrium state, Rayleigh damping was included in the numerical model. Rayleigh damping can be determined as the following Equation (1):

$$
\mathrm{C}=\alpha \mathrm{M}+\beta \mathrm{K}
$$

where $\mathrm{M}$ and $\mathrm{K}$ are the mass matrix and stiffness matrix, respectively. The coefficient $\alpha$ is determined as the lowest natural frequency of the model, which can be achieved using a modal analysis with a subspace eigen-solver in the ABAQUS library. The coefficient $\beta$ is the stiffness proportional damping factor. In this study, only mass proportional Rayleigh damping is considered.

\subsection{Material Properties}

In the collision analysis, the material properties were applied using the revised equations reported in reference Do et al. [7]. These equations were developed using the rigorous dynamic tensile test results on different steels. Equations (2)-(6) were applied to consider the yield plateau and strain hardening. The effect of strain-rate hardening was also included by using Equations (7)-(10). In this paper, the range of strain rates was performed with 10/s, 20/s, 50/s, 70/s, 100/s, to 150/s, as indicated in Figure 2.

$$
\begin{gathered}
\sigma_{t r}=E \varepsilon_{t r} \text { when } 0<\varepsilon_{t r} \leq \varepsilon_{Y, t r} \\
\sigma_{t r}=\sigma_{Y, t r}+\left(\sigma_{H S, t r}-\sigma_{Y, t r}\right) \frac{\varepsilon_{t r}-\varepsilon_{Y, t r}}{\varepsilon_{H S, t r}-\varepsilon_{Y, t r}} \text { when } \varepsilon_{Y, t r}<\varepsilon_{t r} \leq \varepsilon_{H S, t r} \\
\sigma_{t r}=\sigma_{H S, t r}+K\left(\varepsilon_{t r}-\varepsilon_{H S, t r}\right)^{n} \text { when } \varepsilon_{H S, t r}<\varepsilon_{t r}
\end{gathered}
$$

where

$$
\begin{gathered}
n=\frac{\sigma_{T, t r}}{\sigma_{T, t r}-\sigma_{H S, t r}}\left(\varepsilon_{T, t r}-\varepsilon_{H S, t r}\right) \\
K=\frac{\sigma_{T, t r}-\sigma_{H S, t r}}{\left(\varepsilon_{T, t r}-\varepsilon_{H S, t r}\right)^{n}}
\end{gathered}
$$




$$
\begin{gathered}
\frac{\sigma_{Y D}}{\sigma_{Y}}=1+0.3\left(E / 1000 \sigma_{Y}\right)^{0.5}(\dot{\varepsilon})^{0.25} \\
\frac{\sigma_{T D}}{\sigma_{Y D}}=1+\left[0.16\left(\sigma_{T} / \sigma_{Y D}\right)^{3.325}(\dot{\varepsilon})^{1 / 15}\right]^{0.35} \\
\frac{\varepsilon_{H S D}}{\varepsilon_{H S S}}=1+0.1\left(E / 1000 \sigma_{Y}\right)^{1.73}(\dot{\varepsilon})^{0.33} \\
\frac{\varepsilon_{T D}}{\varepsilon_{T}}=1-0.117\left[\left(E / 1000 \sigma_{T}\right)^{2.352}\left(\sigma_{T} / \sigma_{Y}\right)^{0.588}\right](\dot{\varepsilon})^{0.2}
\end{gathered}
$$

where

$\sigma_{t r}, \varepsilon_{t r}:$ true stress and strain, respectively;

$\sigma_{Y, t r}, \sigma_{H S, t r}, \sigma_{T, t r}:$ true yield strength, true hardening start stress, and true ultimate tensile strength, respectively;

$\varepsilon_{H S, t r}, \varepsilon_{T, t r}$ : true hardening start strain and true ultimate tensile strain, respectively;

$\sigma_{T D}, \sigma_{Y D}$ : dynamic ultimate tensile strength and dynamic yield strength, respectively;

$\varepsilon_{T}, \varepsilon_{T D}$ : ultimate tensile strain and dynamic ultimate tensile strain, respectively;

$\varepsilon_{H S D}, \varepsilon_{H S S}:$ dynamic hardening start strain and static hardening start strain, respectively; and $\varepsilon_{Y}, \dot{\varepsilon}$ : yield strain and equivalent strain rate, respectively.

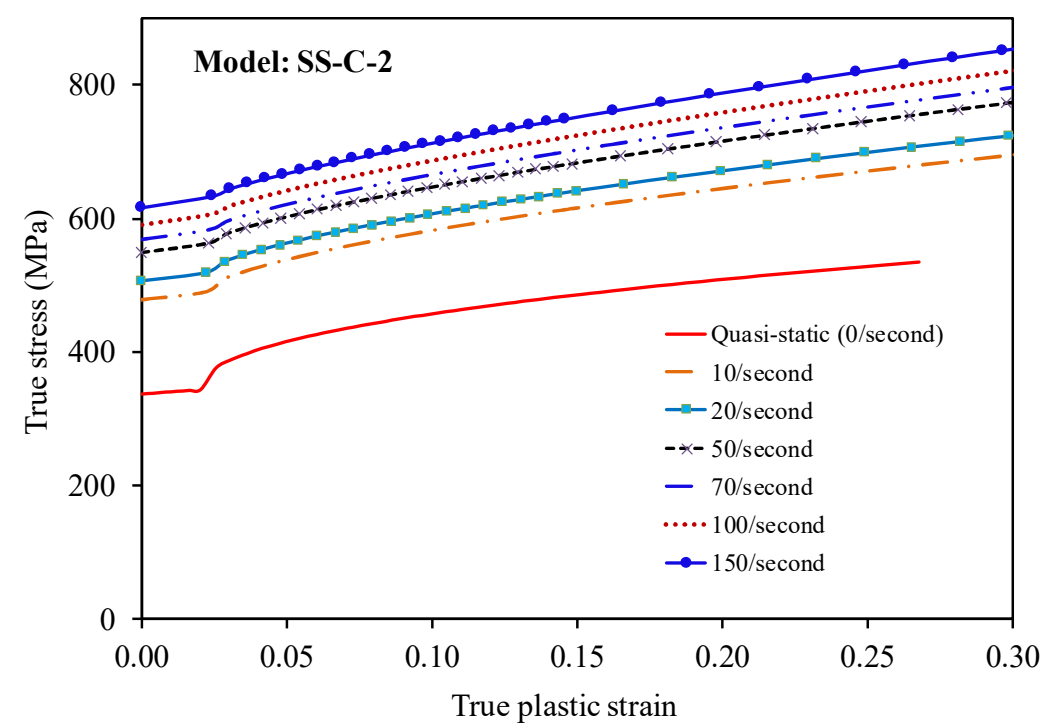

Figure 2. True stress-strain curve applied in FE analysis for RS-C-3 model.

\subsection{Benchmarking Numerical Predictions with Test Results}

Detailed comparisons of numerical results with experimental results for the maximum permanent local denting damages $(d)$ are presented in Table 4 and Figure 3. It should be noted that the permanent local denting $(d)$ value was non-dimensionalized with the radius of each model. In both table and figure, the bias $X_{m}$ (modelling uncertainty factor) is also provided, which is the ratio of numerical results over the test results. Generally, the $X_{m}$ values for all models are close to unity. The mean of the modelling uncertainty factor $\left(X_{m}\right)$ is 1.038 and a quite small coefficient of variation (COV) with $2.98 \%$. These values are shown to exhibit reasonable accuracy of the collision analysis method. Furthermore, the predicted deformed shapes of non-linear finite element analysis and test results are compared for models SS-C-1 and RS-C-1 as indicated in Figure 4. A good agreement of deformed shape is obtained between the numerical results and the test results. Additionally, the numerically predicted longitudinal damage shapes are compared with the measured values in Figure 5. The damage spreads in the longitudinal direction when the flattened part is tilted with a small degree of rotation outward. 
Furthermore, the numerically predicted responses were compared with the test responses using the force-displacement curves, as shown in Figure 6. The overall tendencies and peak force magnitudes were accurately predicted in the numerical analyses. The permanent deflection of model RS-C-1 and RS-C-2 in experimental results was $45.92 \mathrm{~mm}$ and $34.14 \mathrm{~mm}$ while that of numerical results was $44.84 \mathrm{~mm}$ and $36.1 \mathrm{~mm}$, respectively. This means the difference between test and numerical results are around 3\%. Therefore, it can be concluded that the numerical modelling strategy method developed in this study is of high accuracy, and it is can be used for investigating the collision responses of the actual design stiffened cylinders.

Table 4. Comparison of numerical predictions with the experimental results.

\begin{tabular}{ccccccc}
\hline Model & SS-C-1 & SS-C-2 & RS-C-1 & RS-C-2 & RS-C-3 & RS-C-4 \\
\hline Test result, $d(\mathrm{~mm})$ & 36.80 & 43.20 & 45.92 & 34.14 & 35.52 & 47.35 \\
FEA result, $d(\mathrm{~mm})$ & 38.40 & 44.96 & 44.84 & 36.10 & 37.69 & 49.52 \\
Bias (FEA/Test), $X_{m}$ & 1.043 & 1.041 & 0.976 & 1.057 & 1.061 & 1.046 \\
Mean & & \multicolumn{7}{c}{1.038} \\
COV $(\%)$ & & \multicolumn{7}{c}{2.98} \\
\hline
\end{tabular}

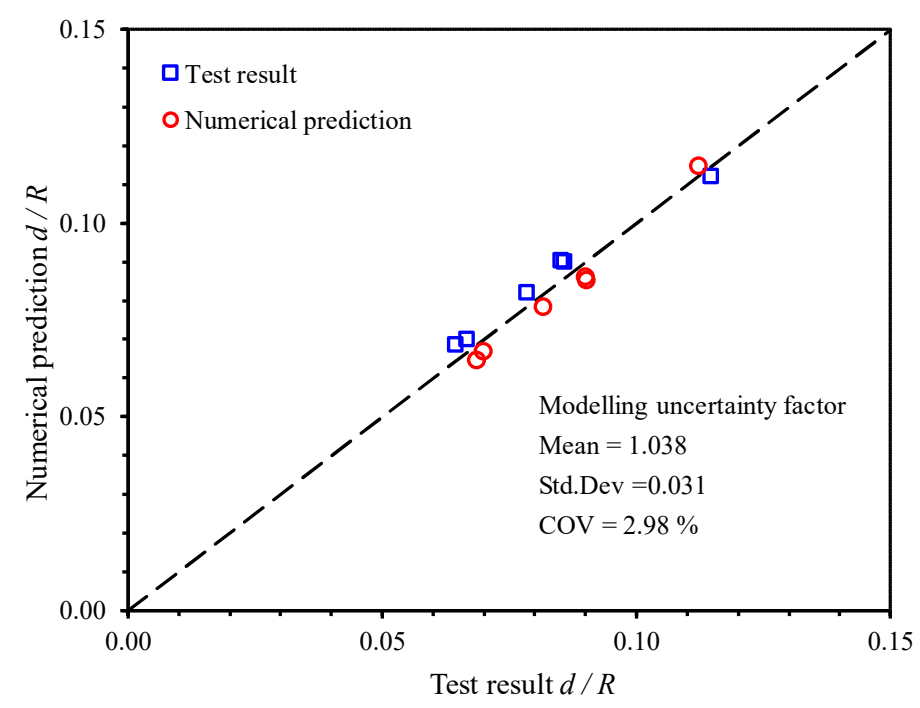

Figure 3. Numerical prediction compared with the test results.
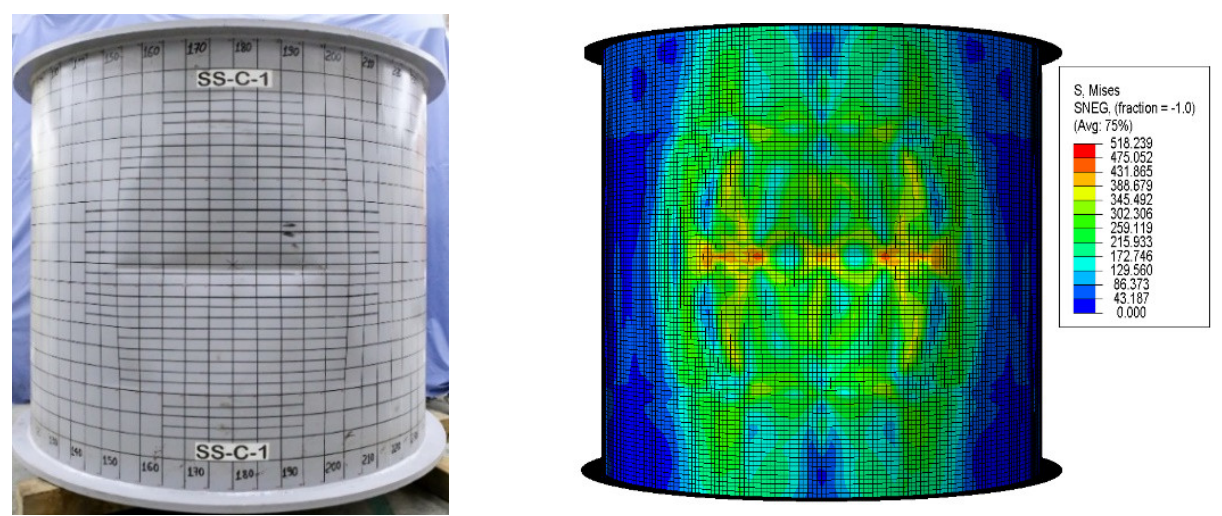

(a)

Figure 4. Cont. 

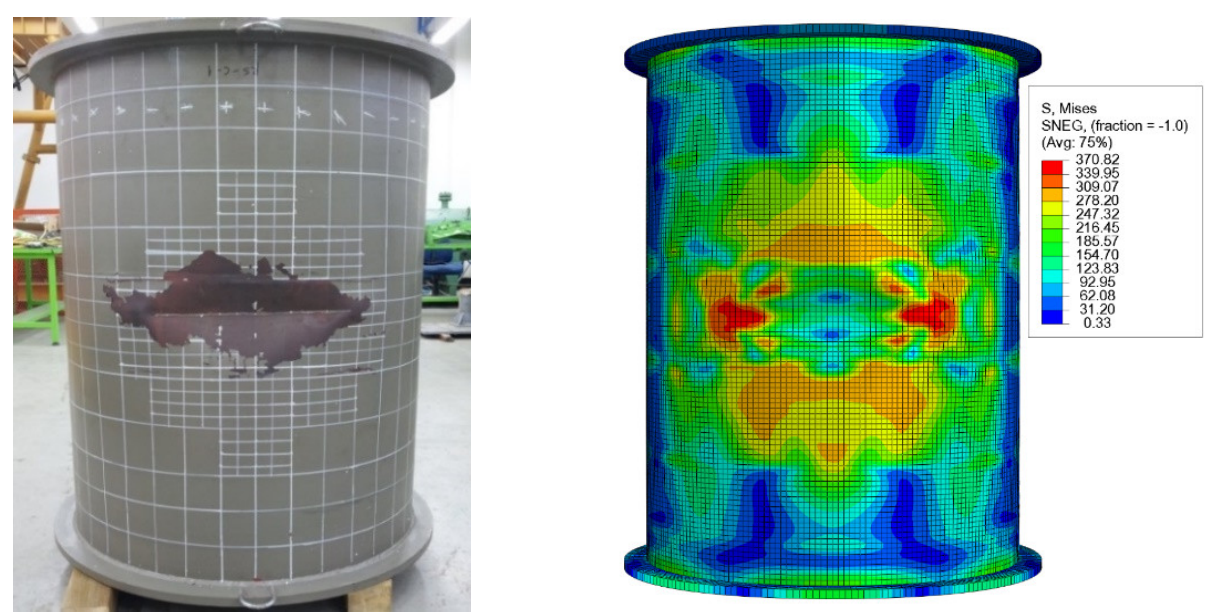

(b)

Figure 4. Comparisons of the test results with numerical predictions: (a) model SS-C-1; (b) model RS-C-1.

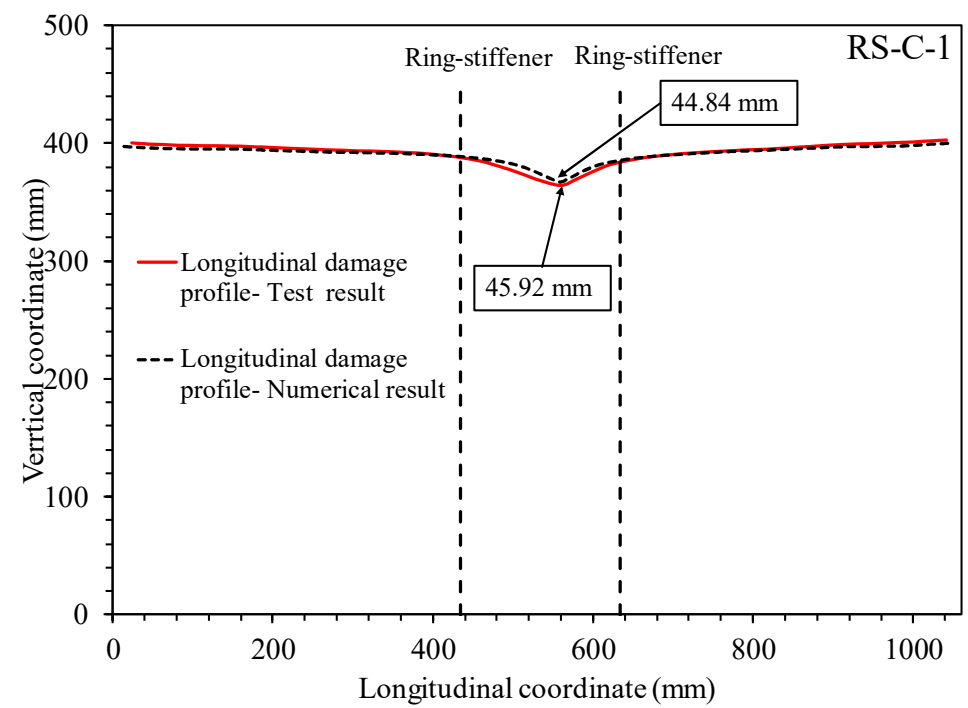

(a)

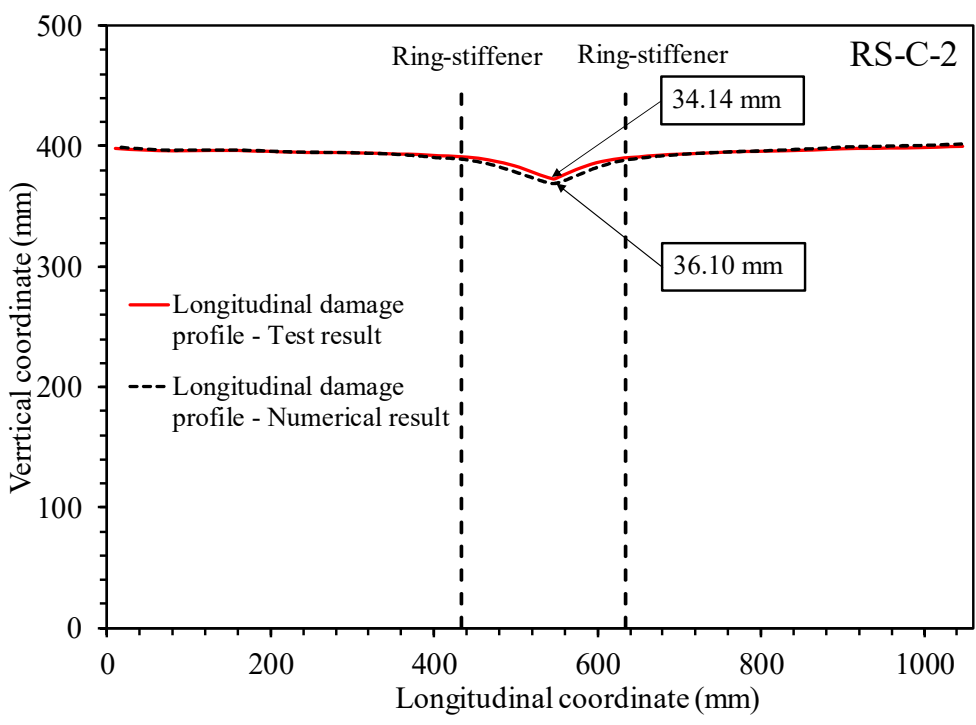

(b)

Figure 5. Comparison of the longitudinal damage profiles obtained from experimental and numerical prediction: (a) model RS-C-1; (b) model RS-C-2. 


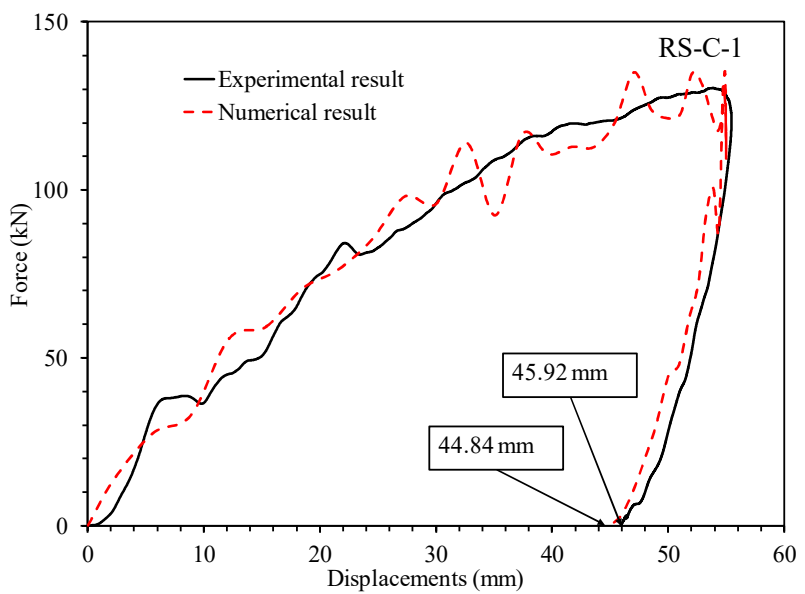

(a)

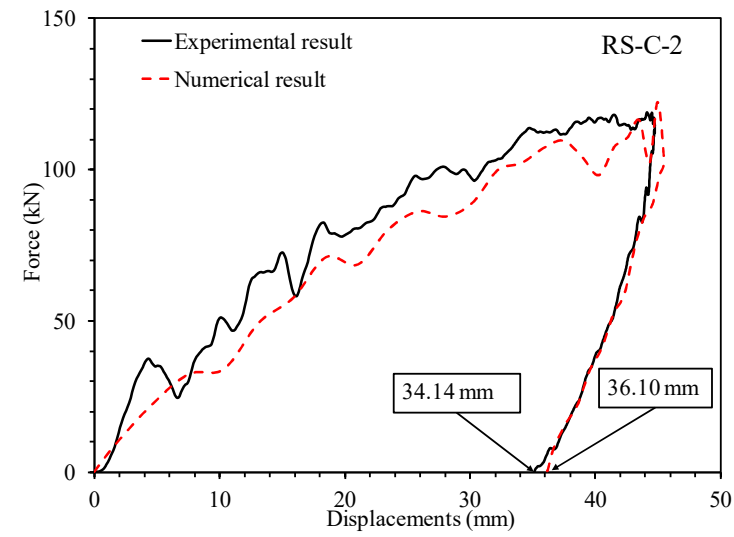

(b)

Figure 6. Predicted force-displacement curve of models compared with the test result: (a) model RS-C-1; (b) model RS-C-2.

\section{Case Studies}

In this section, several parameters are varied to investigate the effects of these changes on the collision response of ring-stiffened cylinders. Not only the effect of the strain-rate hardening definition, impact velocity, and impact locations, but also indenter shape was considered. The material properties and the scantlings of the model are indicated in Table 5. The cylinder was separated into thirteen bays with a T-shaped cross-section of ring-stiffeners. The ratio between cylinder radius and cylinder thickness $(R / t)$ was 159 . It should be noted that the details of the parametric study of mentioned parameters on the stringer-stiffened cylinder can be found in reference Do et al. (2018) [7]. In this section, only ring-stiffened cylinders are investigated.

Table 5. Properties of the ring-stiffened cylinder considered in case study.

\begin{tabular}{ccc}
\hline Property & Symbol & Value \\
\hline Cylinder radius $(\mathrm{mm})$ & $R$ & 3175 \\
Shell thickness $(\mathrm{mm})$ & $t$ & 20 \\
Ring-stiffener spacing $(\mathrm{mm})$ & $L_{s}$ & 840.7 \\
Total cylinder length $(\mathrm{mm})$ & $L$ & 10,500 \\
Number of ring-stiffeners & $n_{r}$ & 12 \\
Ring-stiffener web height $(\mathrm{mm})$ & $h_{r w}$ & 95.2 \\
Ring-stiffener web thickness $(\mathrm{mm})$ & $t_{r w}$ & 11 \\
Ring-stiffener flange width $(\mathrm{mm})$ & $b_{r f}$ & 76.2 \\
Ring-stiffener flange thickness $(\mathrm{mm})$ & $t_{r f}$ & 11 \\
Yield strength $(\mathrm{MPa})$ & $\sigma_{Y}$ & 645 \\
Young's modulus $(\mathrm{GPa})$ & $E$ & 206 \\
$R / t$ & & 159 \\
\hline
\end{tabular}




\subsection{Effect of Strain-Rate Hardening Definition}

In the actual case, the dynamic collision responses are highly sensitive to strain rate because the material strength increases when the strain rate increases. Thus, it is necessary to consider the effect of strain rate on uncertainties in the numerical modelling for improving the accuracy and reliability of the numerical results. In this section, the comparisons of some well-known equations were discussed. Firstly, the Cowper-Symonds [33] plastic constitutive equations as Equation (11), these equations are widely applied for collision behavior of structures. In Equation (10), $\sigma_{Y D}$ and $\sigma_{Y}$ are dynamic yield strength and static yield strength, respectively. $\dot{\varepsilon}_{p}$ is equivalent strain rate while $D$ and $q$ are material constants. Generally, the coefficients $D$ and $q$ were estimated by $D=40.4 \mathrm{~s}^{-1}$ and $q=5$ for mild steel, and $D=3200 \mathrm{~s}^{-1}, q=5$ for high tensile steel. Secondly, Lee and Kim [34] provided the equation to improve the Cowper-Symonds equations by replacing the coefficient $D$ as Equation (12). Finally, the formulations proposed by Cho et al. [35] are also considered as Equations (6)-(9) in the previous section.

$$
\begin{gathered}
\sigma_{Y D}=\sigma_{Y}\left[1+\left(\frac{\dot{\varepsilon}_{p}}{D}\right)^{1 / q}\right] \\
D=\left\{\begin{array}{cc}
92000 \exp \left(\frac{\sigma_{Y}}{364}\right)-193779 \quad \text { for } \sigma_{Y}>271 \\
40 & \text { for } \sigma_{Y} \leq 271
\end{array}\right.
\end{gathered}
$$

The numerical investigation results in terms of force-displacement relation curve are plotted in Figure 7. It is noticeable that the strain-rate hardening definitions are not influenced on the overall response tendencies of all curves. However, it is strongly affected by the maximum permanent deflection because the strain-rate hardening definitions slightly increased or decreased the stiffness of the struck model. When neglecting the strain rate effect (Case 4), the permanent defection is the largest, while that of Case 1 (Cho's equation) is the smallest. The permanent deflection value of Case 4 is larger than that of Case 1 with $12.5 \%$. When the Cowper-Symonds formulation was applied with the coefficient $\mathrm{D}=3200 \mathrm{~s}^{-1}$ (Case 3), and $\mathrm{D}$ was calculated from equations provided by Lee and Kim (Case 2 ), the differences of permanent deflections are $10.9 \%$ and $9.1 \%$ compared with Case 4 , respectively. Therefore, it is recommended that the strain-rate hardening definition should be considered in the numerical analyses for improving the accuracy and reliability of numerical results.

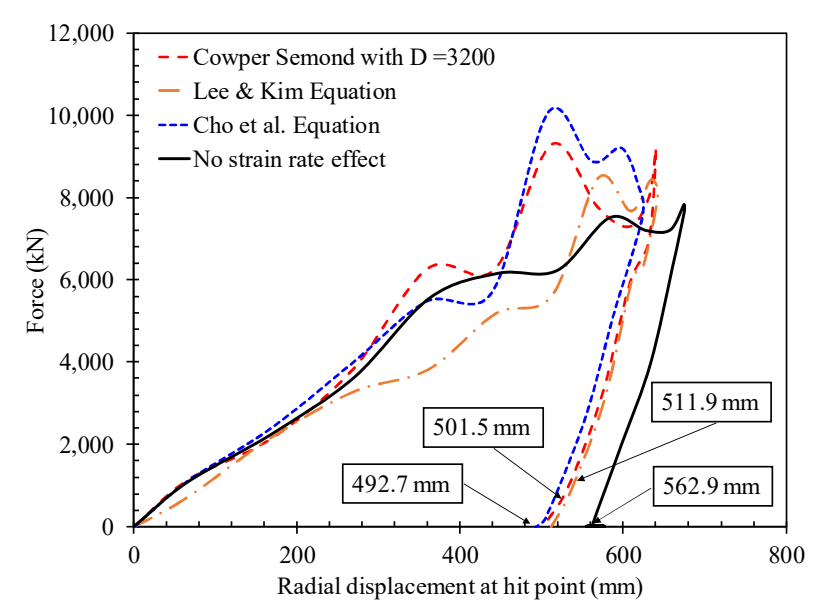

Figure 7. Force- radial displacement curves with various strain-rate hardening definitions.

\subsection{Effect of Impact Velocities}

In this section, the effect of impact velocities was investigated by increasing the initial impact velocity with $2.0 \mathrm{~m} / \mathrm{s}, 4.0 \mathrm{~m} / \mathrm{s}, 6.0 \mathrm{~m} / \mathrm{s}, 8.0 \mathrm{~m} / \mathrm{s}, 10 \mathrm{~m} / \mathrm{s}$, and $15 \mathrm{~m} / \mathrm{s}$. The striking mass was assumed as 100 tons with a hemisphere indenter type. It is evident that the impact energy is proportional to the 
square of impact velocity $v$. Thus, the energy to be dissipated will result in larger deformations for larger impact velocities. Moreover, the strain rate is also linearly proportional to impact velocity $v$. The force-displacement relations for different impact velocities are displayed in Figure 8 . When the impact velocities increase larger than $8 \mathrm{~m} / \mathrm{s}$, the increase in stiffness due to strain rate effect is clear. It is interesting to note that this difference is not only at the initial stage of loading but also remains throughout the impact until the whole impact energy is dissipated. Another important point is that when the impact velocity increases further, the resistance of the ring-stiffened cylinder against denting decreases due to tripping of ring-stiffeners near the impact area.

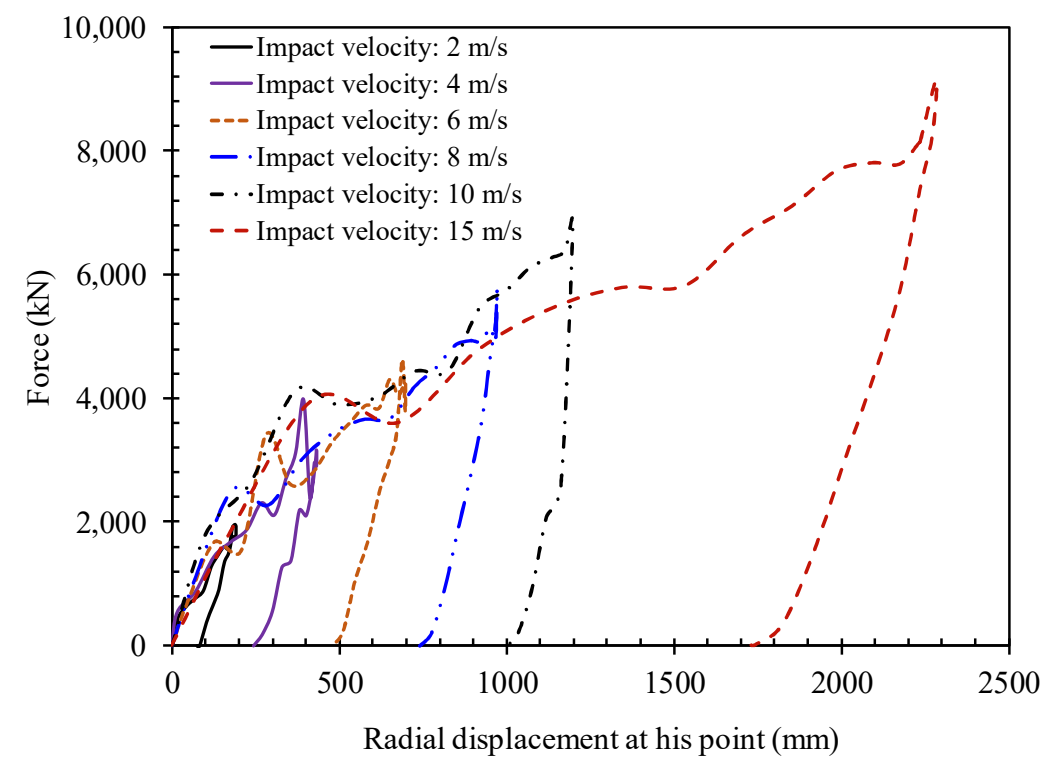

Figure 8. Force-radial displacement curves with various impact velocities.

\subsection{Effect of Impact Locations}

It is clear that the extent local denting damage of the stiffened cylinder was strongly dependent on the impact locations. The permanent dent depth of the unstiffened cylinder was approximately doubled in the ring-stiffened cylinder. Furthermore, permanent dent depth was also significantly reduced with each location in the longitudinal direction of stiffened cylinder. The maximum permanent dent depth almost occurred at the mid-length of the cylinder, and it was decreased gradually to the endplate at the boundary conditions because of the membrane stretching the upper surface of cylinder shell. The reduction factor of permanent dent depth based on the longitudinal direction is illustrated in Figure 9. The impact location factor $\left(C_{L}\right)$ can be quickly estimated as Equation (13), where $x$ is the distance from collision to mid-span of the ring-stiffened cylinder and $L$ is the total length of ring-stiffened cylinder. The mean of this equation is 1.009 together with a COV of $3.64 \%$.

$$
C_{L}=\operatorname{Exp}\left(-1.55\left(\frac{x}{L}\right)^{0.57}\right)
$$

In addition to the effects of impact locations, the collision resistance of the ring-stiffened cylinder was also significantly dependent on the impact angle. The impact angle is created by the skewness of impact striker length and cross-section of stiffened cylinder. For the similar impact location with different impact angles, the maximum permanent dent depth has a trend of increasing with a larger impact angle. The effect the of impact angle is shown in Figure 10. The impact angle factor $\left(C_{\beta}\right)$ can be quickly calculated as Equation (14), where $\beta$ is an impact angle with a unit of radian. The mean of this equation is 0.995 together with $1.95 \%$ of COV.

$$
C_{\beta}=0.139 \beta^{2}-0.0 .437 \beta+1
$$




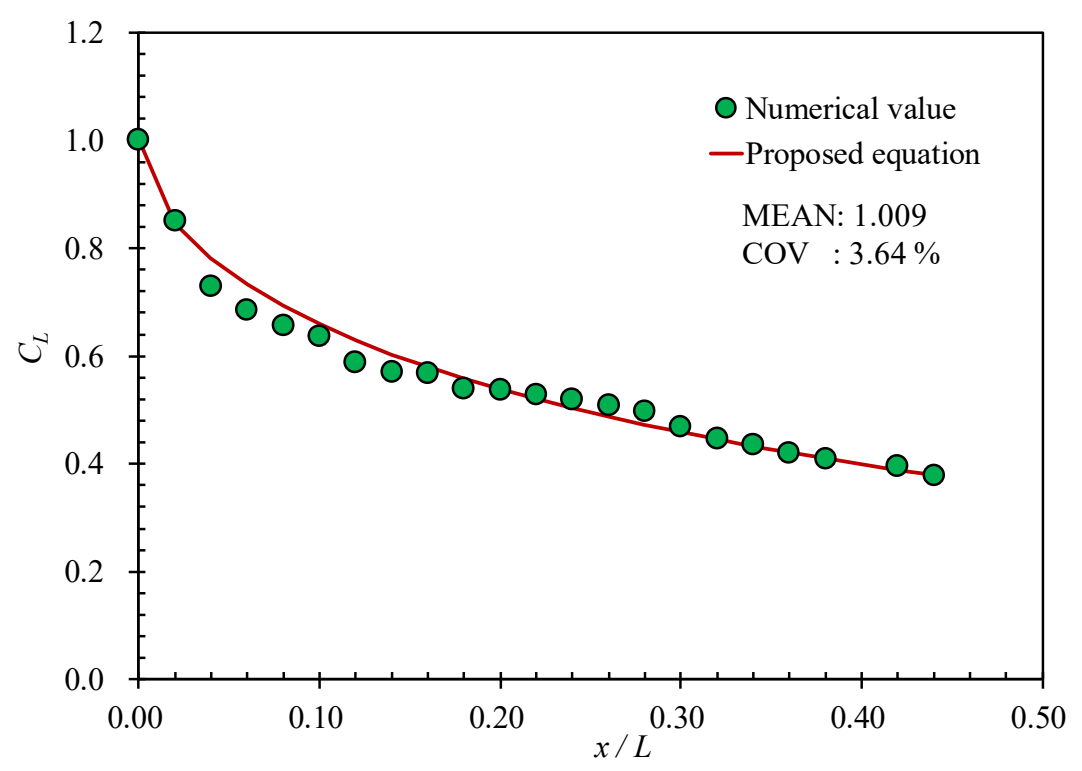

Figure 9. Effects of impact location on the extent damage of ring-stiffened cylinder.

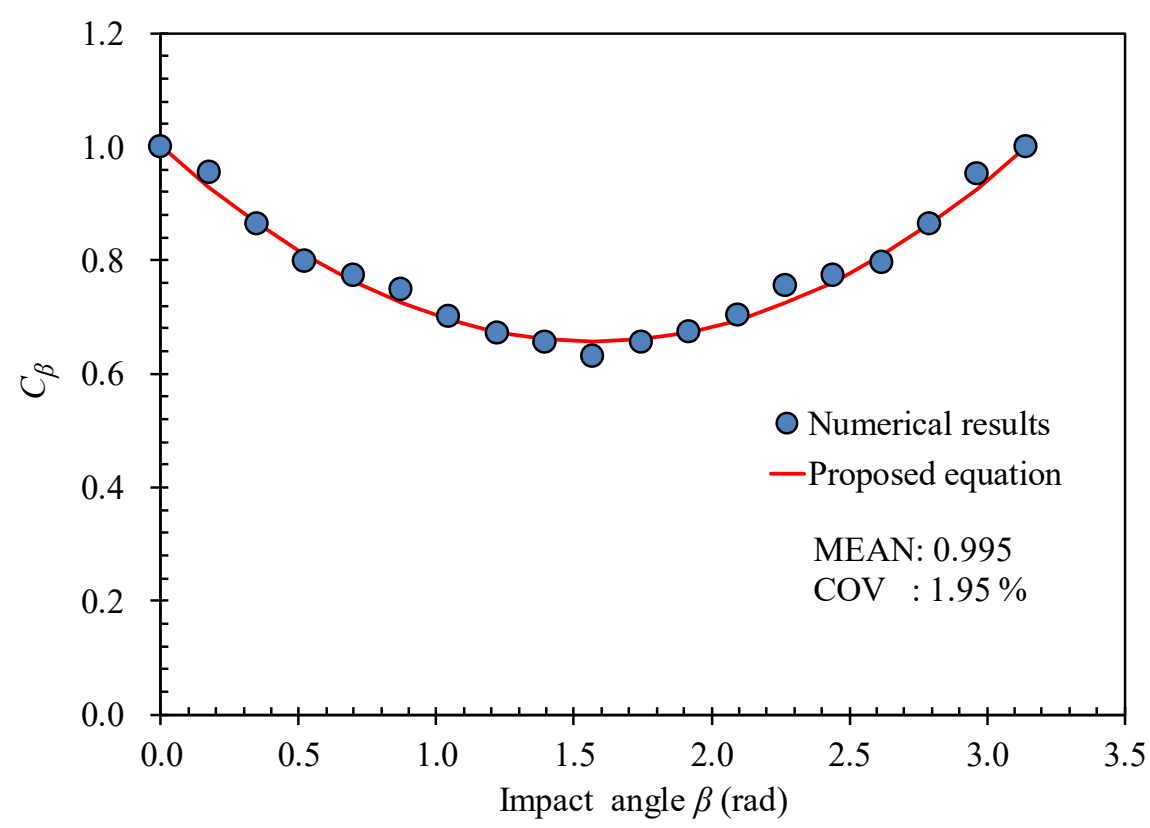

Figure 10. Effects of impact angle on the extent damage of the ring-stiffened cylinder.

\subsection{Effect of Striker Header Shapes}

In practice, ring or/and stringer-stiffened cylinder structures are prone to impact in many ways, such as a striking ship, which may collide with these structures by its bow, stern, or side. For example, the collision scenarios of ship and tension leg platforms are presented in Figure 11. In this study, three types of ship of 4000 tons' class with various bow shapes were applied. Three typical striker header shapes as hemisphere type, knife-edge type, and rectangular type have been investigated, as shown in Table 6. The striking ship was modelled as a rigid body. However, in the actual case, the striking ship may also deform due to collision forces. 


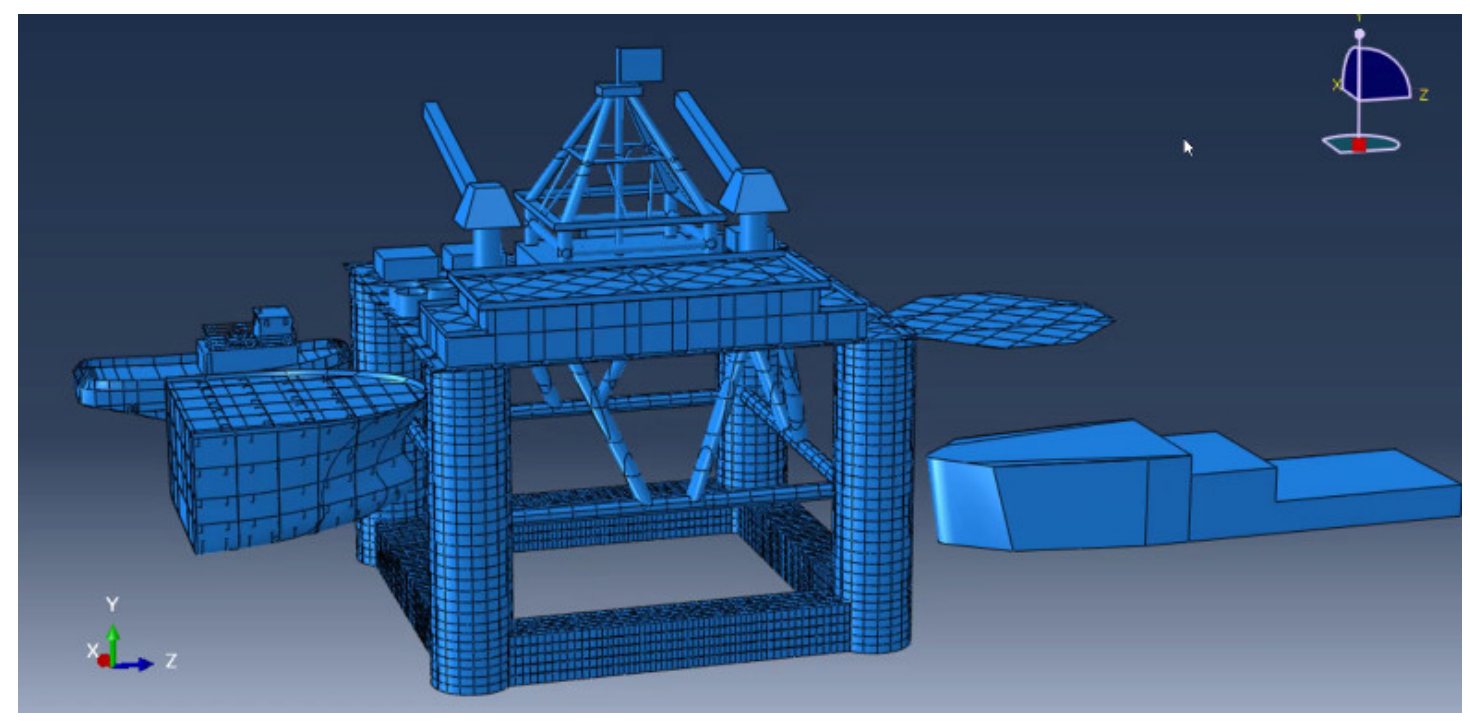

Figure 11. Ship collision scenarios.

Table 6. Main properties of ship collision.

\begin{tabular}{cccc}
\hline Ship Model Used in \\
Simulations
\end{tabular}

The collision simulations were conducted with different impact velocities for assessing the permanent extent damage. It is noted that the diameter and the width of indenting surfaces are the same as the mid-bay length of the struck ring-stiffener cylinder. The corners of the rectangular and knife-edge indenter were filleted. The first case resembles bulbous bow impact and the second case stern or side impact of a unity vessel and offshore accommodation barge vessel, respectively. For the same impact condition, the numerical results for each type of indenter shape are plotted in Figure 12. In this figure, the maximum permanent dent depth $(d)$ was non-dimensional with a radius of cylinder $(R)$, while energy ratio $\left(\lambda_{E}\right)$ was the ratio the kinetic energy of striker $\left(E_{k}\right)$ and energy absorption capacity of struck structure $\left(E_{a}\right)$, as determined in next section. It is clear that the most serious case is a hemispherical indenter type which resembles highly localized loading. The resistance of the cylinder against collision when the load is applied with the hemispherical indenter type was lower than that of the knife-edge and rectangular indenter types by $19 \%$ and $32 \%$, respectively. Furthermore, when the load is applied with a rectangular indenter, the resistance is much better than that of the hemispherical and knife-edge indenter cases. In this case, the load is applied in a very large contact area at the initiation of collision. For the knife-edge indenter, a critical point is the strain concentration at the contact points with the knife-edge ends and the cylinder, as displayed in Figure 13. 


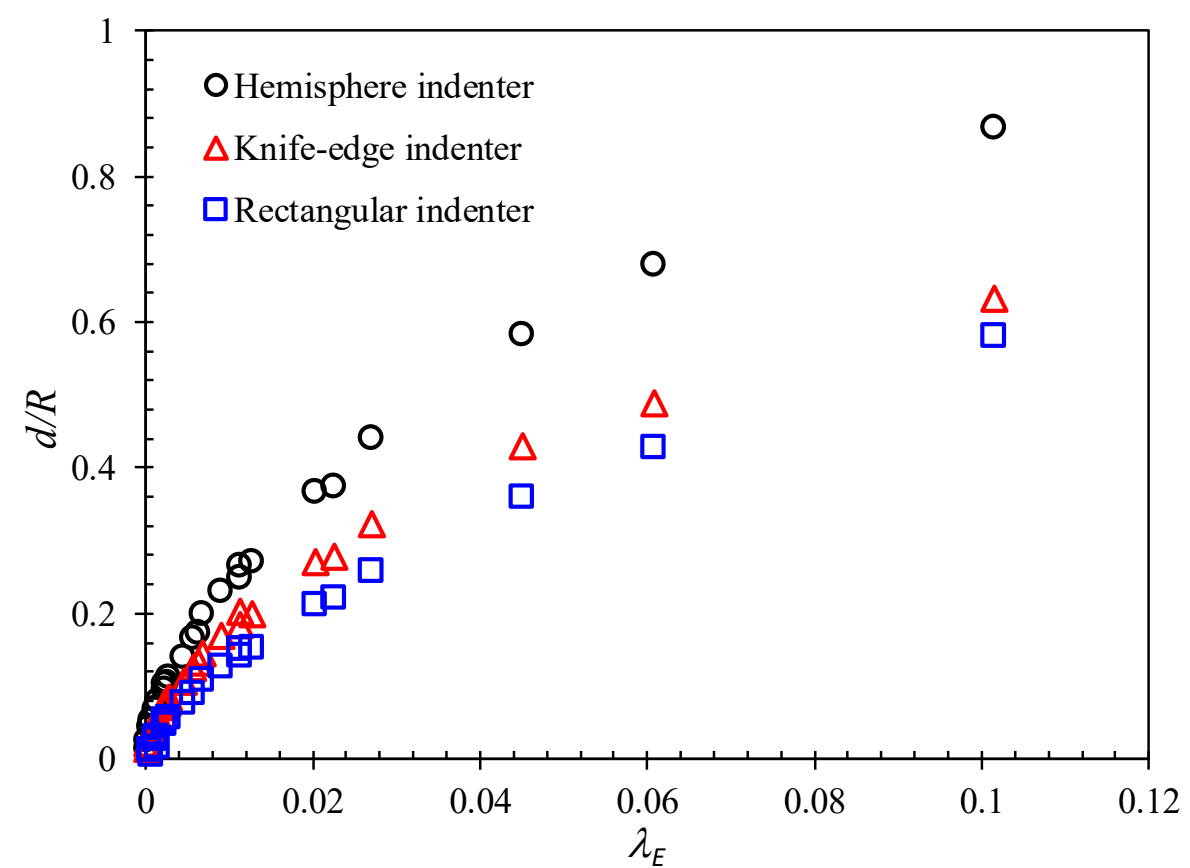

Figure 12. Extent damage of ring-stiffened cylinder for various types of indenter shapes.

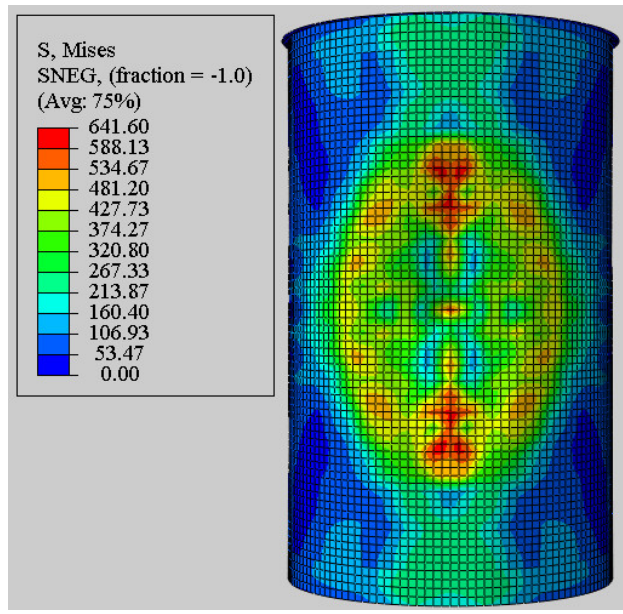

(a)
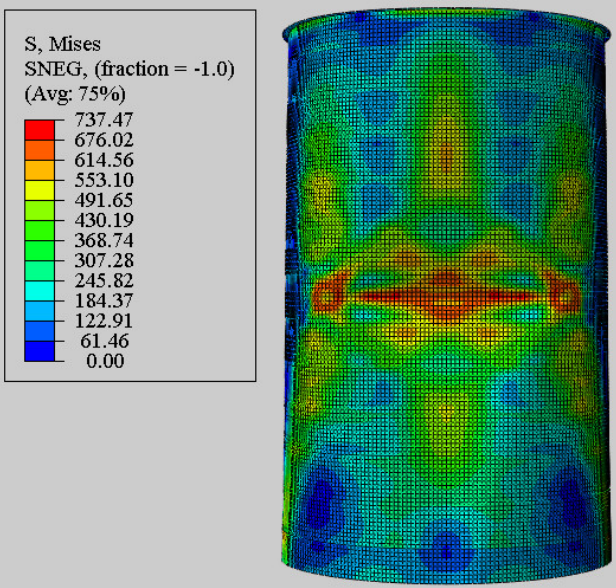

(b)

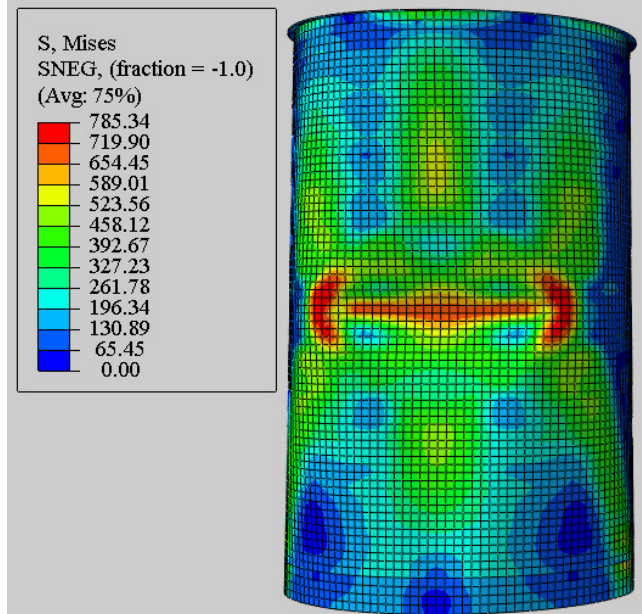

(c)

Figure 13. Deformed shape with different indenter surfaces: (a) hemispherical indenter; (b) knife-edge indenter; and (c) rectangular indenter. 
The behavior of ring-stiffened cylinder structures under impact loadings with a hemispherical indenter was described in Figure 14. The displacement evolutions were divided into three stages: 1-elasto-plastic deformation, 2-elastic spring-back, and 3-elastic vibration (permanent set of damage). Furthermore, the patterns of deformation are shown in Figure 15. The magnitudes of dent depth were increased gradually from $d=0 \mathrm{~mm}$ (intact model) until maximum dent depth $d=1336.4 \mathrm{~mm}$. Then, it was reduced to permanent dent depth with $d=947.2 \mathrm{~mm}$ after the spring-back occurred. It is noted that the typical deformation progresses from the first contact to final permanent deformation also followed the response of displacement-time relationship in Figure 14.

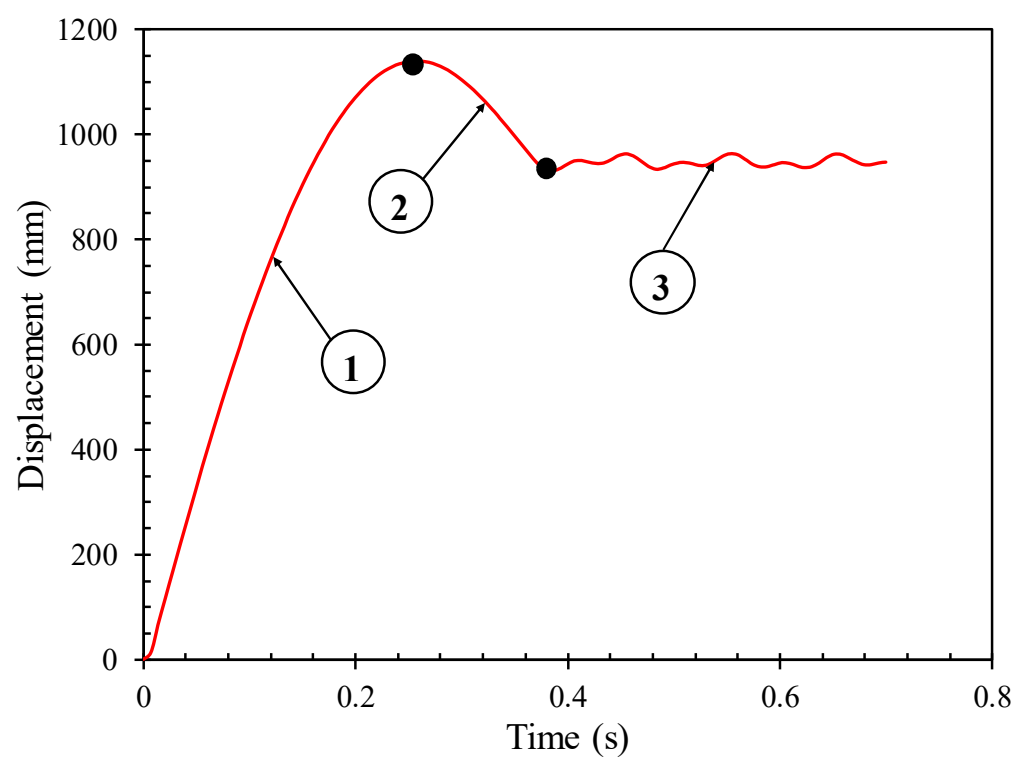

Figure 14. Displacement-time response of model RS-3.

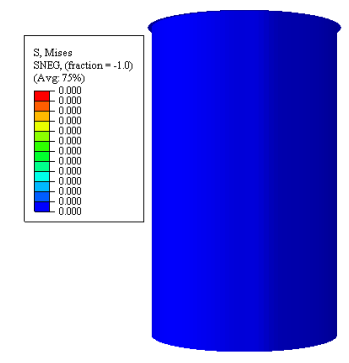

$\operatorname{Intact}(d=0)$

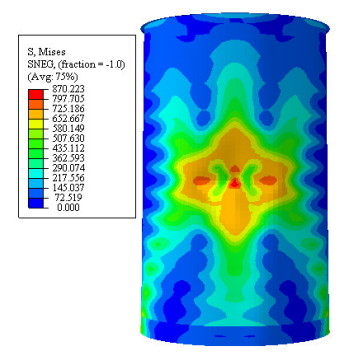

$d=416.2$

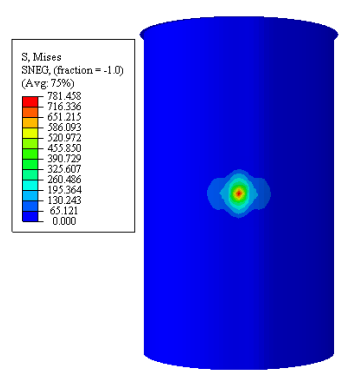

$d=12.5$

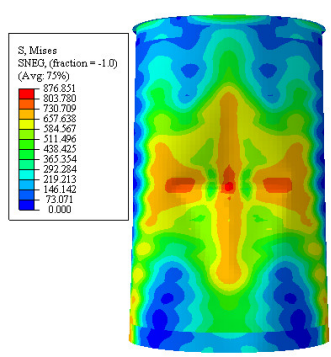

$d=825.5$

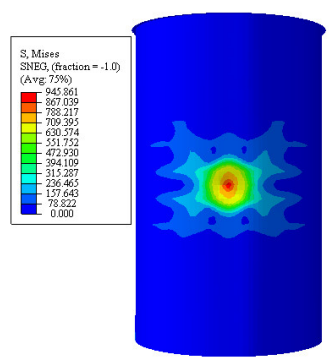

$d=64.9$

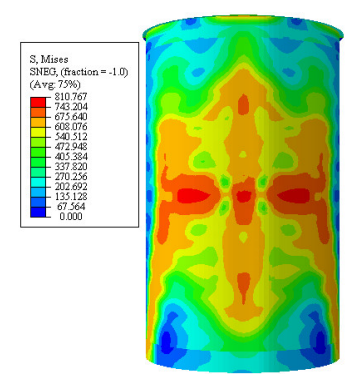

$\max .(d=1336.4)$

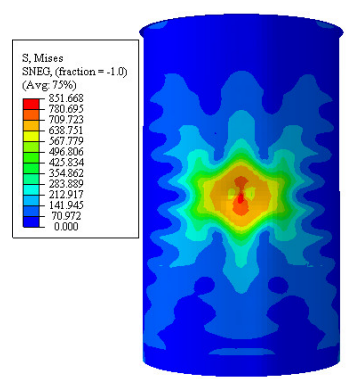

$d=168.7$

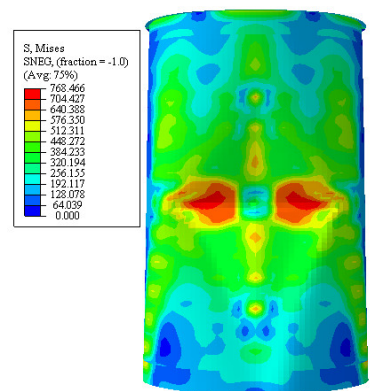

final $(d=947.2)$

Figure 15. Typical deformation progress under collision load of model RS-3 (units: $\mathrm{mm}$ ).

\section{Derivation of Empirical Formulation}

After investigating the effects of various parameters on the impact response of stiffened cylinders in the previous section, the series of parametric studies were performed on actual design scantlings 
of ring- and/or stringer-stiffened cylinders, such as an actual submarine design concept and tension leg platforms in the ABS [37] and API [38] rules. The numerical analysis strategy method developed in the previous section was used. The details of dimension and material properties were provided in Tables 7 and 8 for stringer-stiffened cylinders and ring-stiffened cylinders, respectively. The range of $R / t$ for reference ring-stiffened cylinder was determined from 97 to 454 , while that of reference stringer-stiffened cylinder was from 111 to 475.

Table 7. Material properties and scantlings of the ring-stiffened cylinders.

\begin{tabular}{cccccccccccc}
\hline & Unit & RS-1 & RS-2 & RS-3 & RS-4 & RS-5 & RS-6 & RS-7 & RS-8 & RS-9 & RS-10 \\
\hline$R$ & $\mathrm{~mm}$ & 3100 & 3023 & 3175 & 3100 & 2550 & 5150 & 2500 & 3500 & 550 & 3180 \\
$t$ & $\mathrm{~mm}$ & 30 & 25 & 20 & 23 & 26.2 & 30 & 15 & 12 & 4.97 & 7.0 \\
$L$ & $\mathrm{~mm}$ & 12,600 & 15,240 & 10,500 & 10,320 & 14,850 & 16,250 & 11,250 & 7500 & 1060 & 6650 \\
$L_{S}$ & $\mathrm{~mm}$ & 430 & 3048 & 840.7 & 430 & 450 & 650 & 750 & 400 & 150 & 350 \\
$\sigma_{Y}$ & $\mathrm{MPa}$ & 645 & 754 & 645 & 645 & 827 & 645 & 380 & 276 & 275 & 345 \\
$E$ & $\mathrm{GPa}$ & 206 & 206 & 206 & 206 & 210 & 206 & 205 & 199 & 202 & 199 \\
$n_{r}$ & - & 29 & 5 & 12 & 24 & 33 & 25 & 15 & 19 & 7 & 19 \\
$h_{r w}$ & $\mathrm{~mm}$ & 210 & 214 & 95.2 & 180 & 178 & 262 & 190 & 255 & 40 & 120 \\
$t_{r w}$ & $\mathrm{~mm}$ & 19 & 15 & 11 & 13 & 26 & 16.5 & 20 & 11.5 & 6 & 19 \\
$b_{r f}$ & $\mathrm{~mm}$ & 155 & 280 & 76.2 & 90 & 102 & 231 & 120 & 76.2 & 0 & 90 \\
$t_{r f}$ & $\mathrm{~mm}$ & 19 & 17 & 11 & 23 & 14 & 24 & 20 & 11.5 & 0 & 17 \\
$R / t$ & - & 103 & 121 & 159 & 135 & 97 & 172 & 167 & 292 & 111 & 454 \\
\hline
\end{tabular}

Table 8. Material properties and dimensions of the stringer-stiffened cylinders.

\begin{tabular}{cccccccccc}
\hline & Unit & SS-1 & SS-2 & SS-3 & SS-4 & SS-5 & SS-6 & SS-7 & SS-8 \\
\hline$R$ & $\mathrm{~mm}$ & 3100 & 3025 & 2500 & 4200 & 3025 & 13,320 & 8880 & 9500 \\
$t$ & $\mathrm{~mm}$ & 28 & 19.0 & 15 & 20.0 & 12.0 & 41.5 & 25.0 & 20.0 \\
$L$ & $\mathrm{~mm}$ & 12,500 & 10,240 & 11,250 & 10,500 & 10,240 & $17,500.0$ & 6600 & 26,000 \\
$L_{s}$ & $\mathrm{~mm}$ & 3000 & 2048.0 & 2250 & 3500 & 2048 & 3500.0 & 2200 & 3200 \\
$n_{r}$ & - & 4.0 & 4.0 & 4.0 & 2.0 & 4.0 & 4.0 & 2.0 & 8.0 \\
$h_{r w}$ & $\mathrm{~mm}$ & 210.0 & 214.0 & 190.00 & 700 & 214.0 & 787.5 & 525 & 650 \\
$t_{r w}$ & $\mathrm{~mm}$ & 25.0 & 20.0 & 20 & 12.0 & 15.0 & 37.5 & 25.0 & 20.0 \\
$w_{r f}$ & $\mathrm{~mm}$ & 250 & 200.0 & 150 & 300 & 200 & 450.0 & 300 & 300 \\
$t_{r f}$ & $\mathrm{~mm}$ & 25 & 20.0 & 20 & 16.0 & 15.0 & 45.0 & 30.0 & 20.0 \\
$n_{s}$ & - & 20 & 18.0 & 20 & 36 & 18.0 & 36.0 & 60.0 & 18.0 \\
$h_{s w}$ & $\mathrm{~mm}$ & 130.0 & 160.0 & 150 & 250.0 & 160.0 & 450.0 & 300 & 400 \\
$t_{s w}$ & $\mathrm{~mm}$ & 25.0 & 15.0 & 20 & 12.0 & 11.5 & 37.5 & 15.0 & 20.0 \\
$w_{s f}$ & $\mathrm{~mm}$ & 80.0 & 100.0 & 100 & 90.0 & 100.0 & 285.0 & 190.0 & 200 \\
$t_{s f}$ & $\mathrm{~mm}$ & 25 & 15.0 & 20 & 12.0 & 11.5 & 45.0 & 19.0 & 20.0 \\
$\sigma_{Y}$ & $\mathrm{MPa}$ & 450 & 276.0 & 380 & 355 & 276 & 345.0 & 345 & 645 \\
$E$ & $\mathrm{GPa}$ & 210,000 & 205,000 & 206,000 & 206 & 205,000 & 206,000 & 200,000 & 207,000 \\
$R / t$ & - & 111 & 159 & 167 & 210 & 263 & 321 & 355 & 475 \\
\hline
\end{tabular}

In collision analysis, the rigid hemisphere indenter was applied for generating the damage on the model. For each model, the series of numerical analysis were performed with different impact velocities from $1.0 \mathrm{~m} / \mathrm{s}, 2.5 \mathrm{~m} / \mathrm{s}, 5.0 \mathrm{~m} / \mathrm{s}, 7.5 \mathrm{~m} / \mathrm{s}$, and $10 \mathrm{~m} / \mathrm{s}$. These selected velocities have represented the collisions of offshore installations with dropped objects from platform decks or floating objects, which were large enough to achieve the plastic deformation of the dented stiffened cylinder without any fracture occur. The striker masses were 10 tons, 20 tons, 50 tons, and 100 tons with each velocity, respectively. Additionally, the collision of offshore installations with supply vessels is also considered. The impact velocities were $1 \mathrm{~m} / \mathrm{s}, 2 \mathrm{~m} / \mathrm{s}$, and $3 \mathrm{~m} / \mathrm{s}$. For each velocity, the striker masses were 1000 tons, 3000 tons, 5000 tons, and 7500 tons for the stringer-stiffened cylinder. It should be noted that the added mass was assumed to be $10 \%$ to $40 \%$ of striker mass. Thus, there were a total of 200 and 256 numerical analysis cases for ring-stiffened and stringer-stiffened cylinders, respectively. Subsequently, 
these parametric study results were used to derive empirical equations for predicting the local denting damage of stiffened cylinders.

The procedure to derive empirical formulations for assessment of permanent local denting damage as following steps:

Step 1: Selecting the scantling of actual design example ring- and/or stringer-stiffened cylinders.

Step 2: Performing finite element analysis to assess the collision response of each model.

- Step 3: Preparation of non-dimensional form of geometric properties and collision loadings for applying in the derived formulations.

Step 4: Checking the degree of dependence of explanatory variables.

- Step 5: Performing the regression analysis to find the best-fit curve by using the strongly-influenced parameters in the previous step.

Step 6: Checking the accuracy of the proposed formulations.

- Step 7: Checking the skewness of $X_{m}$ (ratio of the numerical results to the proposed formulation results) against the basic parameters.

\subsection{Ring-Stiffened Cylinder}

To find a suitable dependent basis parameter on which to derive the local denting damage $\delta_{d}\left(\delta_{d}=d / R\right)$, the relationship between $\delta_{d}$ and various appropriate non-dimensional geometric and material property parameters were considered such as $L_{S} / R, L_{s} / t, w_{f} / t_{f}$ and $h_{w} / t_{w}, E / \sigma_{Y}$, and $\lambda_{E}$ (where $L s$ : ring stiffener spacing; $R$ : mean radius; $t$ : shell thickness; and $w_{f}, t_{f}, h_{w}$, and $t_{w}$ are flange width, flange thickness, web height, and web thickness of ring-stiffener, respectively; E: Young's modulus; $\sigma_{Y}$ : yield strength; and $\lambda_{E}$ : energy ratio). Additionally, the combination of different parameters was also evaluated in order to identify the most reasonable method of deriving $\delta_{d}$ formulation, which included Batdorf slenderness $Z=\frac{L^{2}}{R t} / \sqrt{1-v}$; and multiplying of Batdorf coefficient with material properties $\sqrt{Z} \frac{E}{\sigma_{Y}}$ and apart from multiplying the constant of $\frac{\sqrt{L t}}{R} \frac{E}{\sigma_{Y}}$ (where $v$ : Poisson ratio). The degree of dependence and trends are indicated in Figures 16-20. Generally, the trend of parameter of $L_{s} / R, L_{s} / t$, $w_{f} / t_{f}$, and $h_{w} / t_{w}$ has less influence on $\delta_{d}$. Another factor $E / \sigma_{y}$ also has less effect, but in the real case, material properties played an important effect on $\delta_{d}$. Therefore, this parameter will be included in the combination of basic variables. It can be seen that the ratio of energy parameter $\lambda_{E}$ is shown to have the strongest effect on $\delta_{d}$. The energy ratio $\lambda_{E}$ is the ratio of impact kinetic energy of the striker $\left(E_{k}=\frac{1}{2} m v^{2}\right)$ to the energy absorption capacity of the struck structure $\left(E_{a}=\frac{\sigma_{Y}+\sigma_{T}}{2} \varepsilon_{T} V_{s t r}\right)$. This parameter was used for deriving $\delta_{d}$.
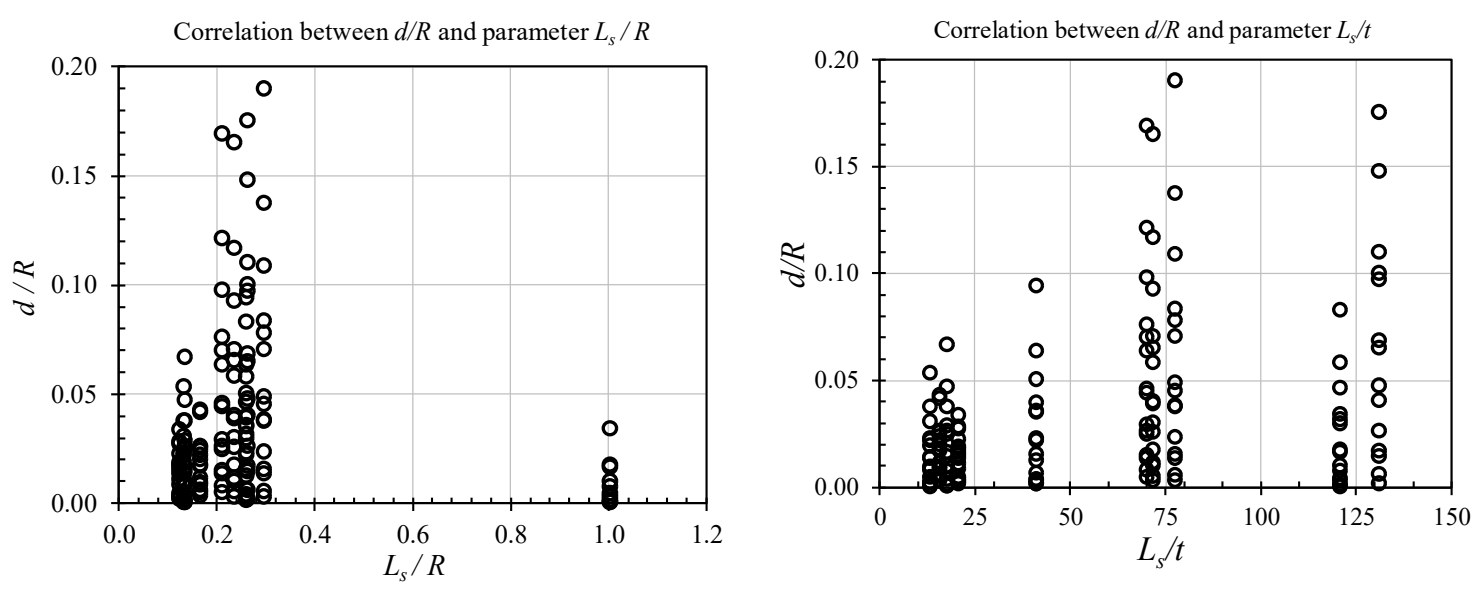

Figure 16. Tendencies of $d / R$ with non-dimensional basic parameters $L_{s} / R$ and $L_{S} / t$ for the ring-stiffened cylinder. 

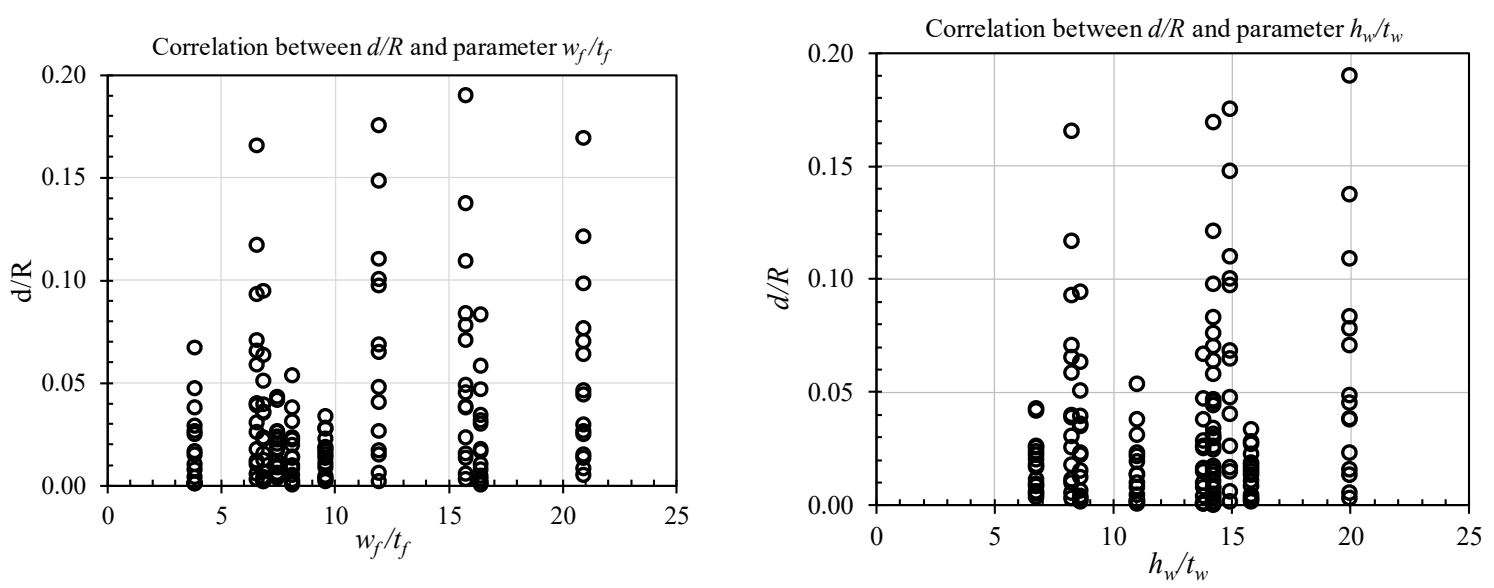

Figure 17. Tendencies of $d / R$ with non-dimensional basic parameters $w_{f} / t_{f}$ and $h_{w} / t_{w}$ for the ring-stiffened cylinder.
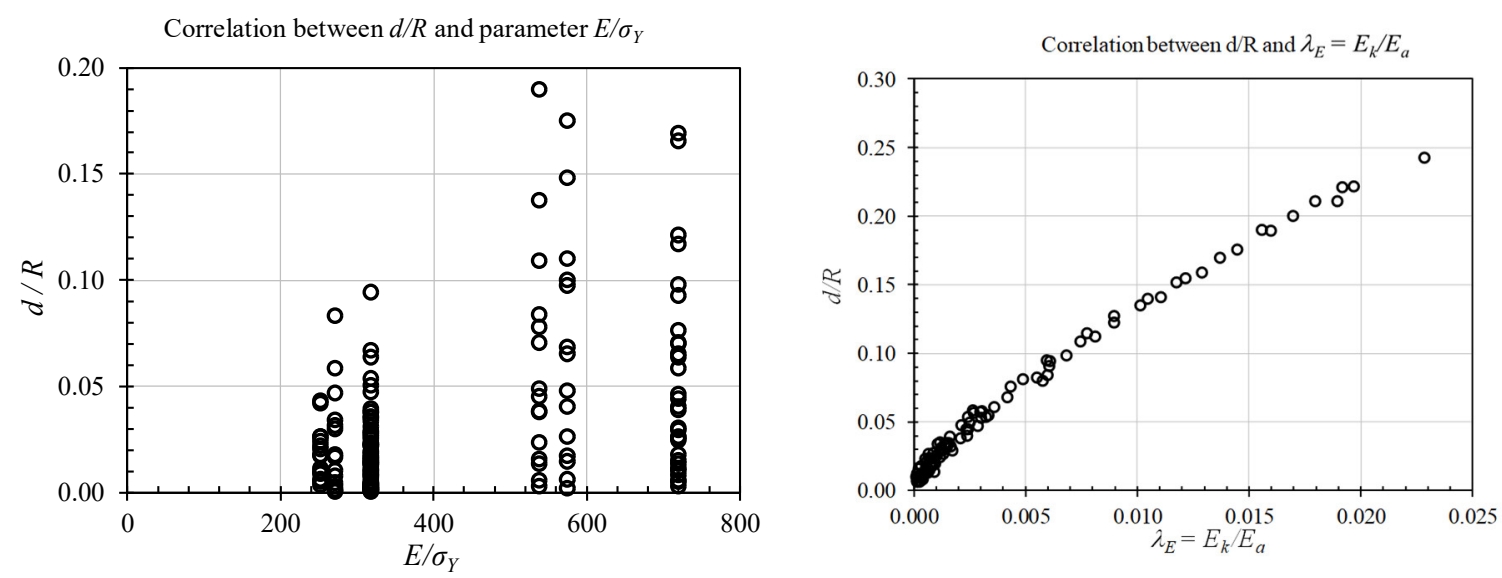

Figure 18. Tendencies of $d / R$ with non-dimensional basic parameters $E / \sigma_{Y}$ and $\lambda_{E}$ for the ring-stiffened cylinder.
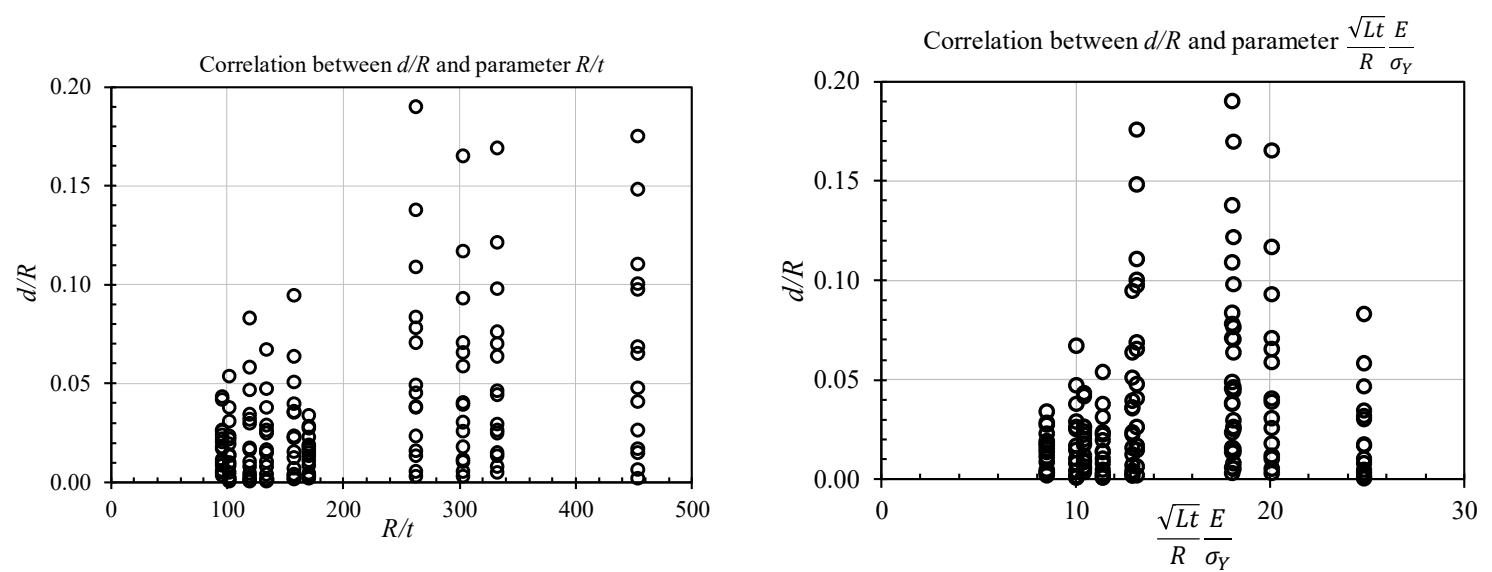

Figure 19. Tendencies of $d / R$ with non-dimensional basic parameters $R / t$ and $\frac{\sqrt{L t}}{R} \frac{E}{\sigma_{Y}}$ for the ring-stiffened cylinder.

After investigating the dependent parameters, the regression analyses were performed using the best-fit curve of numerical values as shown in Figure 21. The mean of the uncertainty modelling factor $\left(X_{m}\right)$ was quite good with 0.996 , while the coefficient of variation (COV) was $6.32 \%$. It is remarkable that the values of maximum permanent dent depth $(d)$ in Figure 21 were less than $0.5 \%$ of the cylinder radius $(R)$, and they were not included because these values can be allowed as the initial 
imperfections according to the upper limit of tolerable initial imperfection of BSI [39] for ring-stiffened cylinders. The simple formulations were derived to predict the maximum of permanent dent depth of ring-stiffened cylinders as shown in Equation (15), which is corresponded to mean curve with discontinue line. When considering the safety design, the design equation is provided in Equation (16), which is determined by multiplying mean curve with (mean $+2 \times \sigma)$ as continue line in Figure 21 . Where $\sigma$ is the standard deviation of mean equation; $\delta_{d}$ is non-dimensional dent depth.
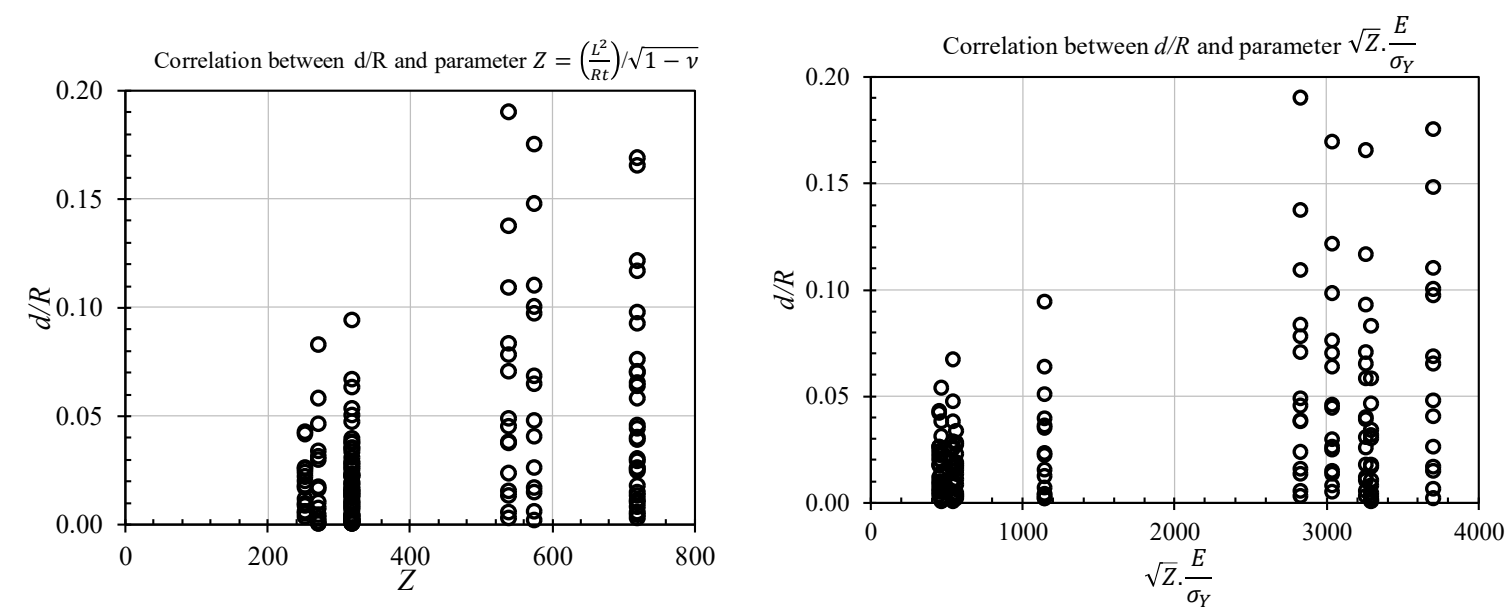

Figure 20. Tendencies of $d / R$ with non-dimensional basic parameters $Z$ and $\sqrt{Z} \frac{E}{\sigma_{Y}}$ for the ring-stiffened cylinder.

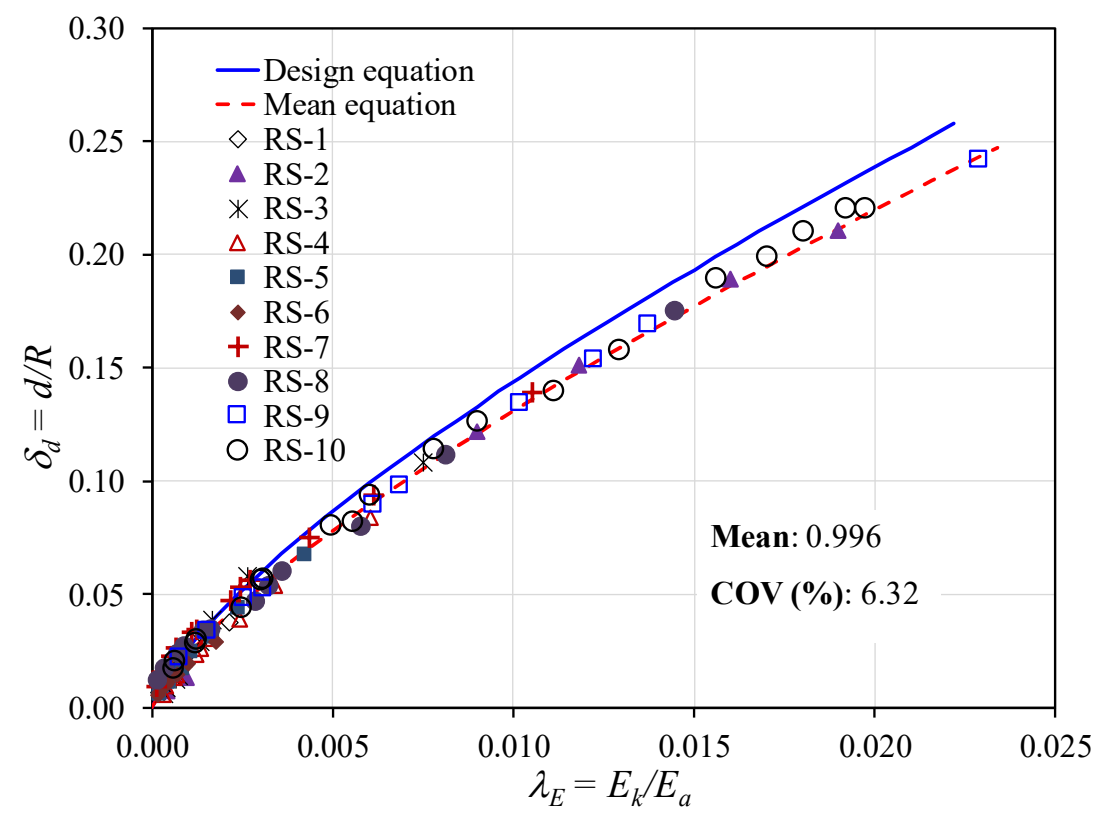

Figure 21. Best-fit curve to predict the extent damage for the ring-stiffened cylinder.

The proposed formulation in Equation (15) developed in this study for predicting the permanent local denting damage includes some parameters: indenter shape factor $\left(C_{s}\right)$, impact location factor $\left(C_{L}\right)$, and impact angle factor $\left(C_{\beta}\right)$. Where the indenter shape factor $\left(C_{s}\right)$ is 1.0 when the striking mass is the hemisphere indenter, while that of 0.81 with the knife-edge indenter and it is 0.68 for the rectangular indenter shape. The impact location factor is determined as Equation (17), which is strongly dependent on the distance of impact position $(x)$ to mid-span of the ring-stiffened cylinder. The effect of impact angle on collision response can be calculated as Equation (18), where $\beta$ is impact angle with unit rad. The next parameter in Equation (15) is energy ratio $\left(\lambda_{E}\right)$, which is evaluated by Equation (19), where $E_{k}$ is the kinetic energy of the striker, as defined in Equation (20), and $E_{a}$ is the energy absorption capacity 
of struck structure, as provided in Equation (21). The structure volume was quickly determined in Equation (22). Additionally, the ultimate strength $\left(\sigma_{T}\right)$ and ultimate strain $\left(\varepsilon_{T}\right)$ can be calculated by Equations (23)-(26) for general steel and marine steel, respectively. These Equations (23)-(26) are empirical equations and derived using the results of 7500 tensile test specimens [35].

$$
\begin{gathered}
\delta_{d}=\frac{d}{R}=4.91 C_{S} C_{L} C_{\beta}(E)^{0.71} ; \text { Mean equation } \\
\delta_{d}=\frac{d}{R}=5.16 C_{S} C_{L} C_{\beta}(E)^{0.71} ; \text { Design equation }
\end{gathered}
$$

where

$C_{S}:$ indenter shape factor $\left(C_{S}=1\right.$ : Hemisphere indenter; $C_{S}=0.81:$ Knife-edge indenter;

$C_{S}=0.68:$ Rectangular indenter),

$C_{L}$ : impact location factor, and

$C_{\beta}$ : impact angle factor.

$$
\begin{gathered}
C_{L}=\operatorname{Exp}\left(-1.55\left(\frac{x}{L}\right)^{0.57}\right) \\
C_{\beta}=0.139 \beta^{2}-0.0 .437 \beta+1
\end{gathered}
$$

where

$x$ : distance from collision to mid-span of the ring-stiffened cylinder,

$L$ : total length of the ring-stiffened cylinder, and

$\beta$ : impact angle (rad)

$$
\begin{gathered}
E=\frac{E_{k}}{E_{a}} \\
E_{k}=\frac{1}{2} m v^{2} ; \text { Kinetic energy } \\
E_{a}=\frac{\sigma_{Y}+\sigma_{T}}{2} \varepsilon_{T} V_{\text {str }} ; \text { Strain energy absorption capacity } \\
V_{\text {str }}=V_{\text {shell }}+V_{\text {ring-stiffener }}=A . L+V_{\text {ring-stiffener }}
\end{gathered}
$$

- For general structural steel:

$$
\begin{gathered}
\frac{\sigma_{T}}{\sigma_{Y}}=\left\{1+0.664\left(\frac{E}{1000 \sigma_{Y}}\right)^{2.4}\right\} \\
\frac{\varepsilon_{T}}{\varepsilon_{Y}}=336\left(\frac{E}{1000 \sigma_{Y}}\right)^{2.52}
\end{gathered}
$$

- For marine structural steel:

$$
\begin{gathered}
\frac{\sigma_{T}}{\sigma_{Y}}=\left\{1+1.3\left(\frac{E}{1000 \sigma_{Y}}\right)^{2.5}\right\} \\
\frac{\varepsilon_{T}}{\varepsilon_{Y}}=320\left(\frac{E}{1000 \sigma_{Y}}\right)^{1.76}
\end{gathered}
$$


As mentioned in the previous section, after deriving the proposed equation, the final step is to check the skewness of $X_{m}$ against the basic parameters using the cross-validation charts. This step is vital in the regression diagnostic process to derive the design formula. If skewness strongly occurred with basic parameters, it means that these parameters should be included in the proposed formulation. The plotting of $X_{m}$ against basis non-dimensional parameters $\left(R / t, L_{s} / R, h_{w} / t_{w}, w_{f} / t_{f}, E / \sigma_{Y}\right.$, and $L_{c} / R$ ) is illustrated in Figures 22-24. It can be seen that there was no apparent skewness and no sharpness trend line in these figures. Therefore, it is concluded that the accuracy and reliability of the proposed formulations are acceptable to predict the maximum permanent local denting damage under dynamic collision.
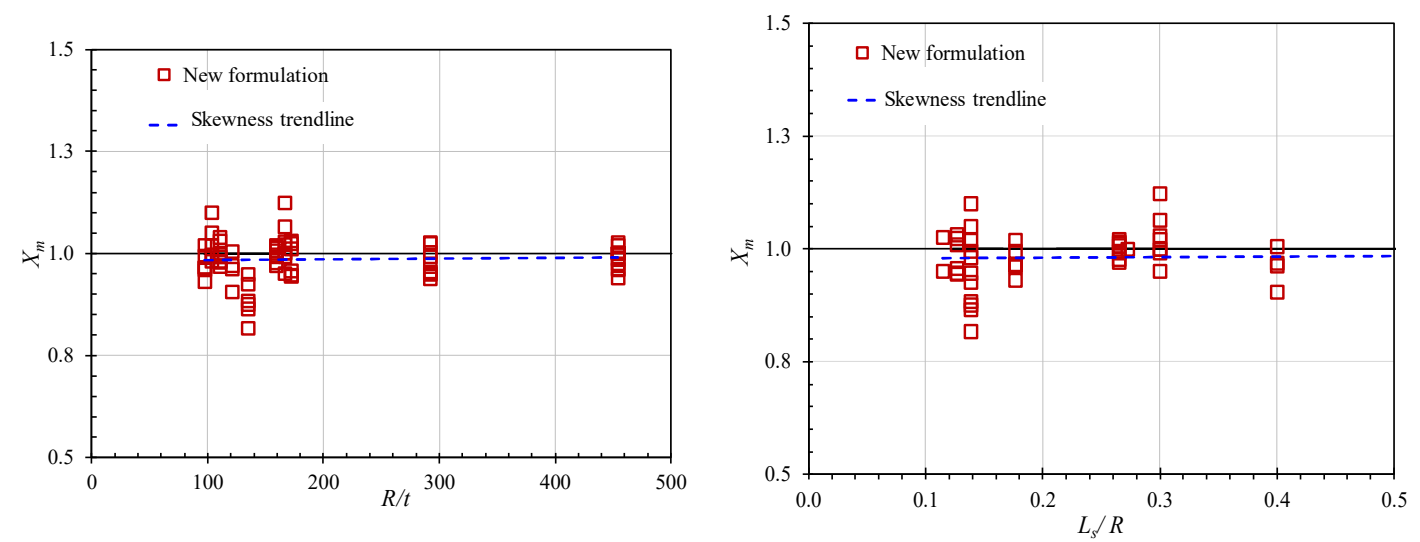

Figure 22. Skewness of the proposed formula against the basic parameters $R / t$ and $L_{S} / R$ for the ring-stiffened cylinder.
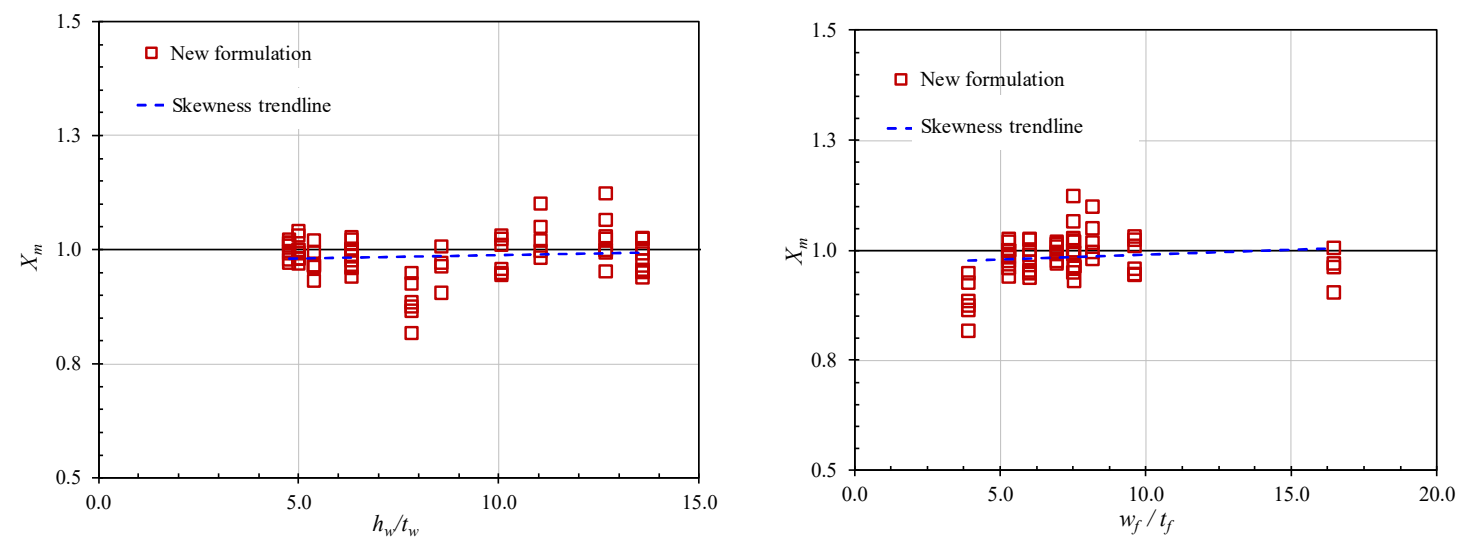

Figure 23. Skewness of the proposed formula against the basic parameters $h_{w} / t_{w}$ and $w_{f} / t_{f}$ for the ring-stiffened cylinder.
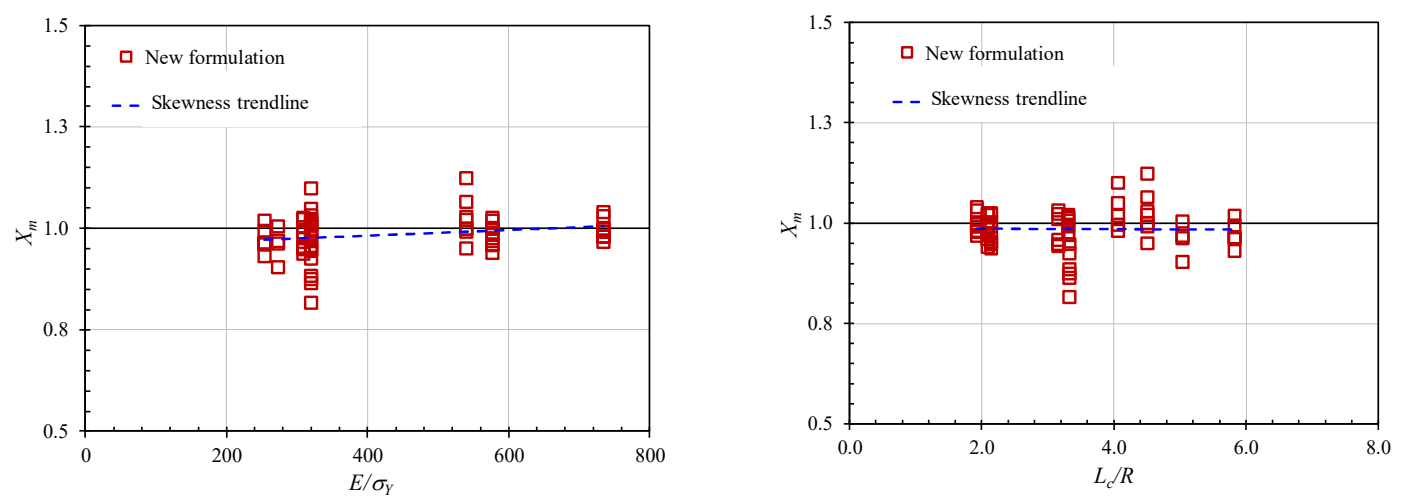

Figure 24. Skewness of the proposed formula against the basic parameters $E / \sigma_{Y}$ and $L_{C} / R$ for the ring-stiffened cylinder. 


\subsection{Stringer-Stiffened Cylinder}

The procedures to derive the formulation to predict the local denting damage of a stringer-stiffened cylinder are similar to procedures applied to a ring-stiffened cylinder in the previous Section 4.1. First, the correlations between $\delta_{d}$ and various parameters were checked. It is included non-dimensional geometric $\left(L_{s} / R, L_{s} / t, h_{r w} / t_{r w}, h_{s w} / t_{s w}\right.$, and $\left.w_{s f} / t_{s f}\right)$ and material property parameters $\left(E / \sigma_{Y}\right.$ and $\left.\lambda_{E}\right)$ and combinations of variable parameters $\left(Z=\frac{L^{2}}{R t} / \sqrt{1-v}\right.$ : Batdorf slenderness; $\sqrt{Z} \frac{E}{\sigma_{Y}}$ and $\left.\frac{\sqrt{L t}}{R} \frac{E}{\sigma_{Y}}\right)$. The results also indicated that energy ratio $\lambda_{E}$ is the strongest parameter affected by $\delta_{d}$. Then, the regression analysis was performed, and Equations (27)-(30) were derived as functions of the energy ratio $\left(\lambda_{E}\right)$ to predict the maximum permanent dent depth of the stringer-stiffened cylinder under dynamic mass impact. It is noteworthy that the maximum permanent dent depth values $(d)$ smaller than $0.25 \%$ of the cylinder diameter $(D)$ were not considered, which corresponded to the upper limit of tolerable imperfection for stringer-stiffened cylinders by API [38]. The Equation (27) is a mean equation while that of Equation (28) is the design equation. It is noted that when considering the purposes of the safety design under hazard and risk conditions of marine structures, the design equation, which is determined by multiplying the mean curve with (Mean $+2 \times$ Standard deviation), should be used. These proposed formulations could be used easily for the purposes of the initial design without any time-consuming FEM analysis.

The accuracy of the proposed formula was quite good, with $X_{m}$ (ratio of predicted values from Equation (27)/numerical values) of 0.987 together with a COV of $8.60 \%$. In these equations, the effect of striker header shapes and impact locations, as well as impact angles, was also considered as the reduction factor $C_{S}, C_{L}$, and $C_{\beta}$, respectively. The most severe case is when the load is applied through a hemispherical indenter, which resembles highly localized point loading with $C_{S}=1$, then $C_{S}=0.74$ and $C_{S}=0.63$ for the knife-edge indenter and rectangular indenter, respectively. Therefore, the proposed formulation was derived based on the most severe case of a hemispherical indenter. The effects of impact locations and impact angles were considered as Equations (29) and (30), respectively.

$$
\begin{gathered}
\delta_{d}=\frac{d}{R}=3.59 \operatorname{CSCLC} C_{\beta}(E)^{0.68} ; \text { Mean equation } \\
\delta_{d}=\frac{d}{R}=4.16 \operatorname{CSCL} C_{\beta}(E)^{0.68} ; \text { Design equation }
\end{gathered}
$$

where

$C_{S}$ : indenter shape factor $\left(C_{S}=1\right.$ : Hemisphere indenter; $C_{S}=0.74$ : Knife-edge indenter;

$C_{S}=0.63:$ Rectangular indenter),

$C_{L}$ : impact location factor, and

$C_{\beta}$ : impact angle factor.

$$
\begin{gathered}
C_{L}=\operatorname{Exp}\left(-9.91 \frac{x}{L}\right) \\
C_{\beta}=0.114 \beta^{2}-0.346 \beta+1
\end{gathered}
$$

The skewness of the proposed formulation results to the numerical analysis results $\left(X_{m}\right)$ with various parameters is plotted in Figures 25-27. There is no apparent skewness in these figures. Therefore, these basic parameters should be not considered for inclusion in the design of the proposed formulation to predict the maximum permanent dent depth of the stringer-stiffened cylinder under dynamic mass impact. 

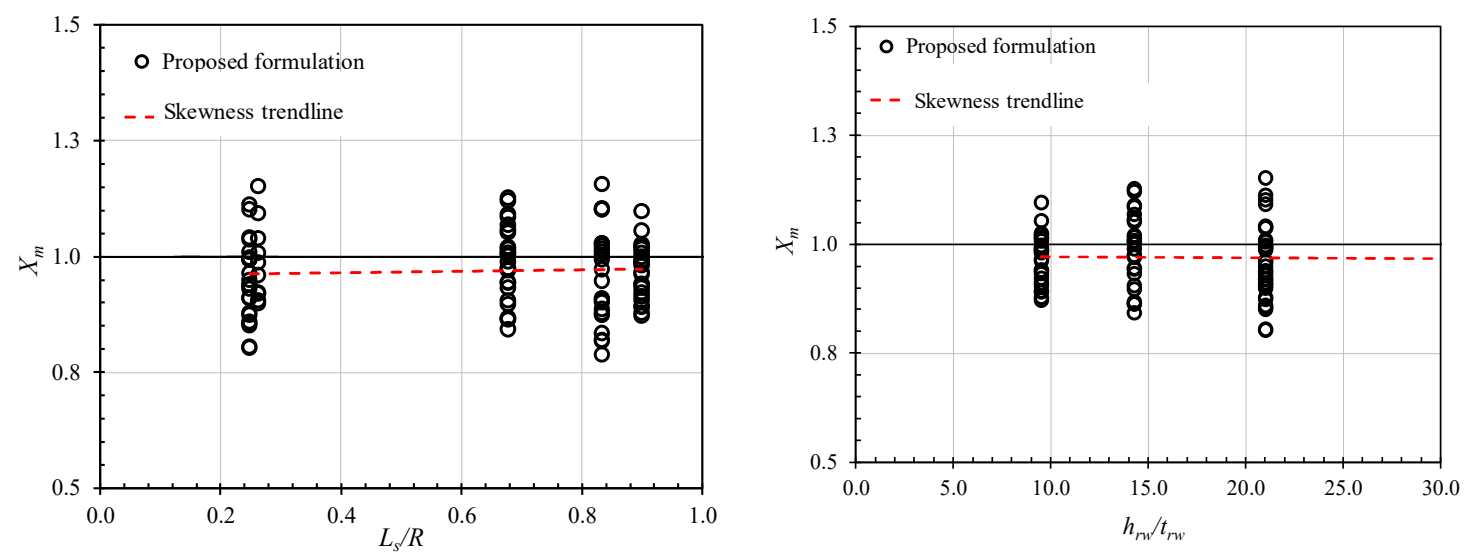

Figure 25. Skewness of the proposed formula against the basic parameters $L_{S} / R$ and $h_{r w} / t_{r w}$ for the stringer-stiffened cylinder.
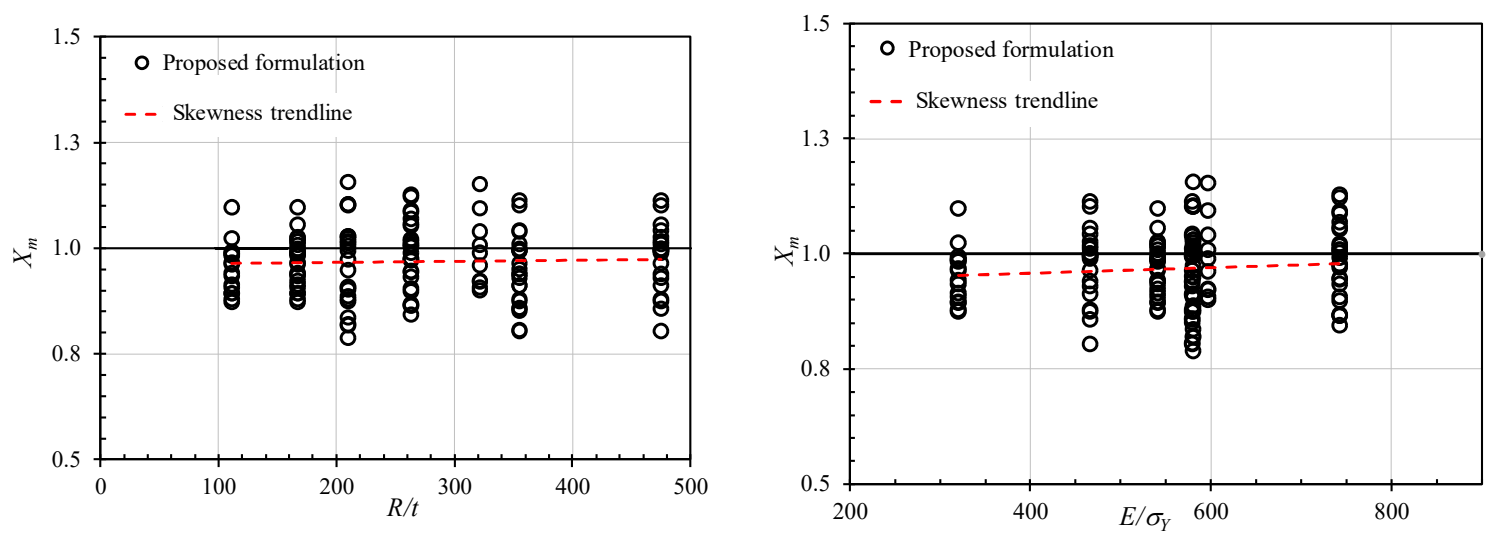

Figure 26. Skewness of the proposed formula against the basic parameters $R / t$ and $E / \sigma_{Y}$ for the stringer-stiffened cylinder.
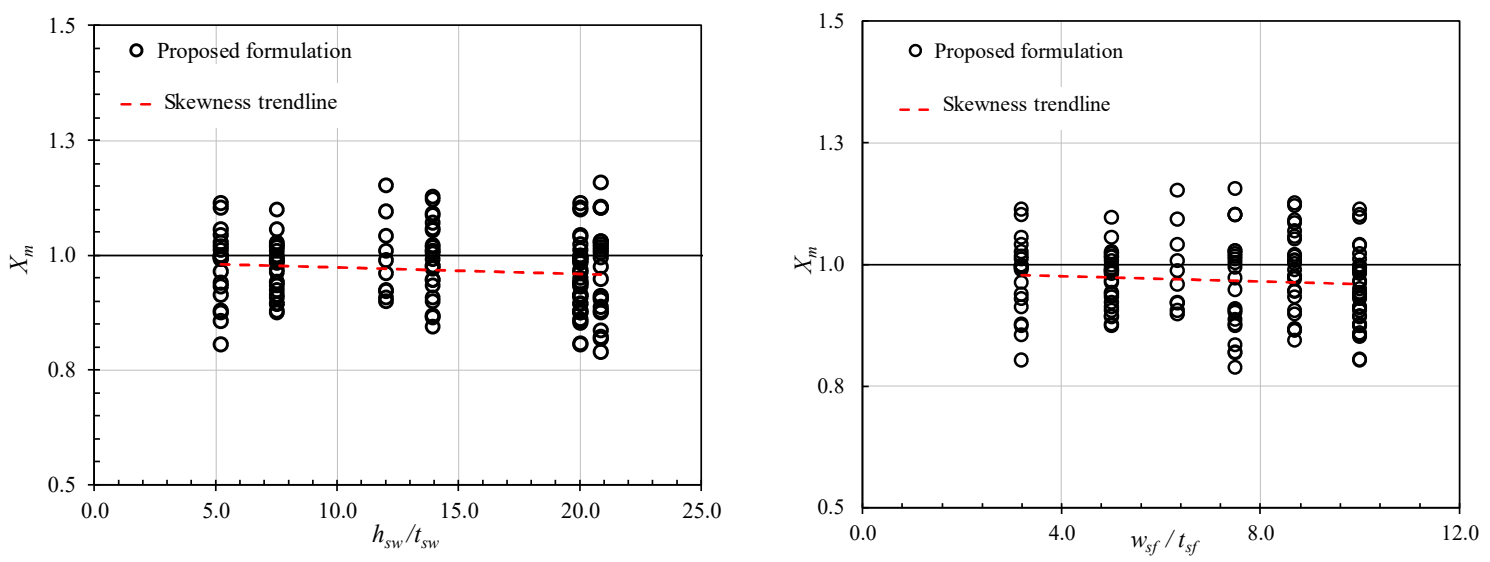

Figure 27. Skewness of the proposed formula against the basic parameters $h_{s w} / t_{s w}$ and $w_{s f} / t_{s f}$ for the stringer-stiffened cylinder.

\section{Accuracy of the Proposed Formulation}

To validate the accuracy and reliability of the proposed formulation for the extent damage predictions of the ring- and/or stringer-stiffened cylinders, the comparisons between the proposed formulation and the available test results and the existing analytical equations in the literature were conducted. 


\subsection{Comparison with Available Test Results}

A comparison of the proposed formulation predictions and available experimental results is summarized in Table 9. The bias (proposed formulation values/test values) was smaller than $8.1 \%$ for all cases. Furthermore, the mean of $X_{m}$ for all the models was 1.040 together with a COV of $2.74 \%$. This means that the proposed formulation provides a good accuracy for the predicting of maximum local dent depth of stiffened cylinder structures under dynamic mass impact. Therefore, in actual cases, when the striking mass, impact velocity, and geometry of the cylinder structures and material properties were provided, the maximum permanent local dent depth was quickly predicted by using the proposed formulations, (Equation (15) for ring-stiffened cylinders and Equation (26) for stringer-stiffened cylinders, respectively).

Table 9. Comparison of the proposed formulation results with the test results.

\begin{tabular}{ccccccc}
\hline Model & SS-C-1 & SS-C-2 & RS-C-1 & RS-C-2 & RS-C-3 & RS-C-4 \\
\hline Test result, $d(\mathrm{~mm})$ & 36.80 & 43.20 & 45.92 & 34.14 & 35.52 & 47.35 \\
Proposed formulation, $d(\mathrm{~mm})$ & 39.77 & 44.67 & 48.53 & 33.95 & 36.89 & 49.07 \\
Bias (Prop. Formulation/Test), $X_{m}$ & 1.081 & 1.034 & 1.057 & 0.994 & 1.039 & 1.036 \\
Mean of $X_{m}$ & \multicolumn{7}{c}{1.040} \\
COV (\%) & \multicolumn{7}{c}{2.74} \\
\hline
\end{tabular}

\subsection{Comparison with Other Existing Formulae}

Prior to comparing the newly derived formulation with other formulations, let us re-visit the existing equations in the open literature for predicting the permanent dent depth of stiffened cylinders. The equations by Hoo Fatt and Wierzbicki [13], provided the smeared model based on the equivalent thickness. However, the shortcoming were that the membrane resistances of cylinder shell increased significantly when the thickness and fully plastic moment of the cylinder shell were replaced with the equivalent thickness and equivalent bending moment per length, respectively. The force-displacement relation is then expressed as Equation (31):

$$
P=16 m_{0} \frac{t_{e q}}{t} \sqrt{\frac{\pi}{3} \frac{d}{R} \frac{D}{t}}
$$

where

$m_{0}$ : fully plastic bending moment of the cylinder wall per unit length; $m_{0}=\frac{\sigma_{0} t^{2}}{4}$,

$d$ : permanent dent depth at the impact point,

$\sigma_{0}$ : average flow stress; $\sigma_{0}=\frac{\sigma_{Y}+\sigma_{T}}{2}$, and

$t_{\text {eq }}$ : equivalent thickness; $t_{\text {eq }}=\sqrt{\frac{4 m_{e q}}{\sigma_{0}}}$.

Equation (31) was improved by Cerik et al. [2]. He followed the assumption of Hoo Fatt and Wierzbicki [13], but only $m_{0}$ was replaced with $m_{e q}$. The force-displacement response for the ring-stiffened cylinder is obtained as Equation (32):

$$
P=8 m_{e q} \sqrt{\frac{\pi d}{8 t}}+N_{0} \sqrt{\frac{\pi t d}{2}}
$$

where

$m_{\text {eq }}$ : equivalent bending moment per length; $m_{\ell q}=\frac{M}{l_{r}}$,

$M$ : bending moment; $l_{r}$ : ring-stiffener spacing, and

$N_{0}$ : plastic axial resistance per unit width; $N_{0}=\sigma_{0} t$.

Unlike the case of ring-stiffeners, the stringer affects both membrane resistance and circumferential bending resistance. Thus, the stringers were smeared to obtain an equivalent shell thickness and 
then the stringers were treated as beams and adding the resistance of each stringer was added to the resistance of the cylinder shell. The force-displacement response for stringer-stiffened cylinder is obtained as Equation (33):

$$
P_{\text {total }}=P_{c y l}+\sum_{i=1}^{n_{s}} P_{s t r}=16 m_{0} \frac{t_{e q}}{t} \sqrt{\frac{\pi}{3} \frac{d}{R} \frac{D}{t}}+\sum_{i=1}^{n_{s}} 2 P_{0} \frac{w}{h_{s w}}
$$

where

$w$ : beam deflection; $h_{s w}$ : stringer web height,

$n_{s}$ : number of stringers in damaged effect zone,

$P_{0}$ : plastic collapse resistance in bending; $P_{0}=\frac{8 M_{p}}{L}$,

$M_{p}$ and $L$ are plastic bending moment and total length of the stringer-stiffener, respectively;

$P_{\text {total }}:$ resistance of the stringer-stiffened cylinder, and

$P_{c y l}:$ resistance of the cylinder shell.

In the current study, the force-displacement relationship for both ring and stringer-stiffened cylinders can be expressed as the following equations:

- $\quad$ Ring-stiffened cylinder:

In the current study, the force-displacement response of the proposed formulation is expressed in Equations (34) and (35) for mean equation and characteristic equation, respectively. It can be obtained by the derivation of Equations (15) and (16) with respect to $d$.

$$
\begin{gathered}
P=0.15 \frac{E_{a}}{\left(C_{S} C_{L} C_{\beta} R\right)^{1.41}} d^{0.41} ; \text { Mean equation } \\
P=0.14 \frac{E_{a}}{\left(C_{S} C_{L} C_{\beta} R\right)^{1.41}} d^{0.41} ; \text { Design equation }
\end{gathered}
$$

- $\quad$ Stringer-stiffened cylinder:

The force-displacement response of the proposed formulation is expressed in Equations (27) and (28) for mean equation and characteristic equation, respectively. It can be quickly achieved by the derivation of Equations (36) and (37) with respect to $d$.

$$
\begin{aligned}
& P=0.224 \frac{E_{a}}{\left(C_{S} C_{L} C_{\beta} R\right)^{1.471}} d^{0.471} ; \text { Mean equation } \\
& P=0.18 \frac{E_{a}}{\left(C_{S} C_{L} C_{\beta} R\right)^{1.471}} d^{0.471} ; \text { Design equation }
\end{aligned}
$$

The force-displacement responses obtained using proposed formulations were compared with that of the experimental results and other existing equations to assess the validity of the approach and any shortcomings, as illustrated in Figure 28. The proposed formulation from Fatt and Wierzbicki (1991) is highly over-predicted, while that of Cerik et al. (2015) equation is under-predicted with experimental results. However, the initial part of the Cerik curve matched well with the test results. For the force-displacement response curve of the proposed formulation, when Equation (15) was equated to the impact energy in the experimental result, maximum dent depth at peak force can be obtained. In comparison with the force-displacement values, it predicted well with experimental results for the proposed mean Equation (34). When considering the safety design in risk conditions, the proposed design Equation (35) was under predicted. 


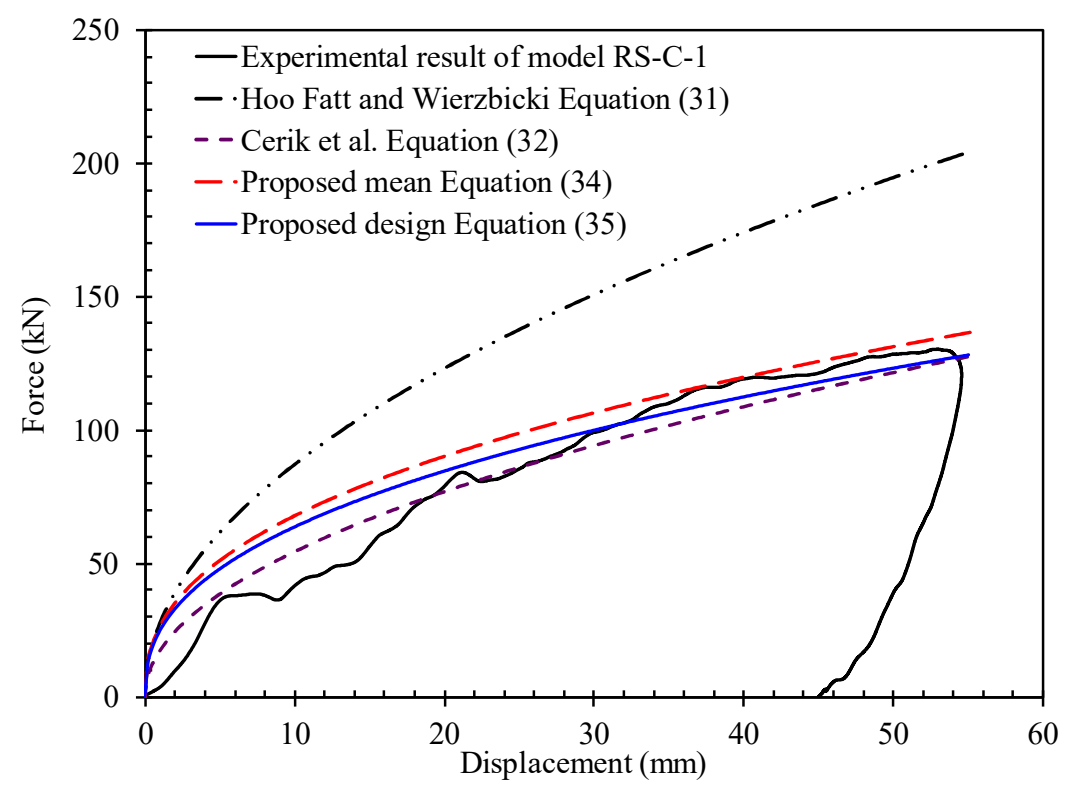

(a)

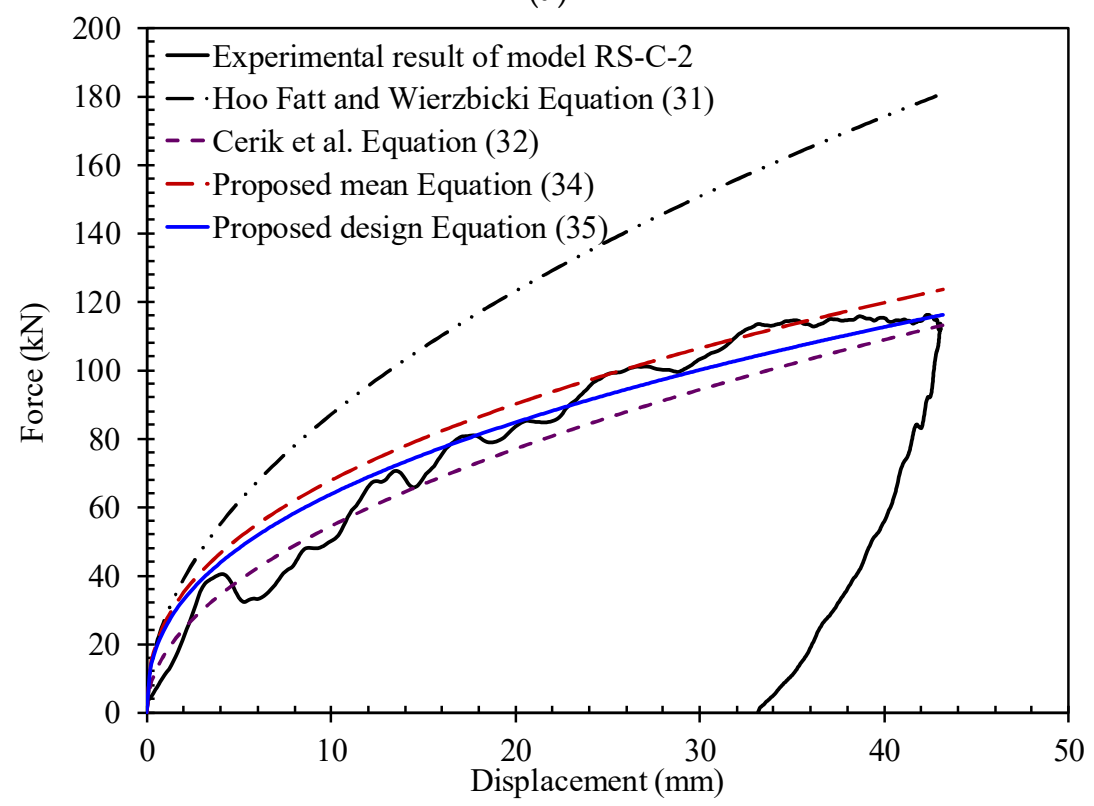

(b)

Figure 28. Comparison of predicted force-displacement relations using proposed formulations with other existing formulations for ring-stiffener cylinders: (a) Model RS-C-1; (b) Model RS-C-2.

The proposed formulations were compared with the numerical results and existing formulae of the two stringer-stiffened cylinder models (SS-C-1 and SS-C-2), as shown in Figure 29. It is noted that the fluctuations in numerical results could not be captured for all models. Further, the initial resistance, which is the collapse resistance of the first stringer and attached plating, was a bit higher in the numerical results. This should be attributed to the strain rate effect and vibration during impact processes. Nevertheless, the overall tendencies of the numerical response are well captured by both models. It is clear that force-displacement relations of Hoo Fatt and Wierzbicki (1991) and Cerik et al. (2015) is over-predicted. However, the proposed formulation predicted well. The main difference of the proposed formulation was that the slope of the force-displacement curve did not decrease much as in the existing formulae. It is believed that for a simple tool this inaccuracy is acceptable. This is important when designing the stringer-stiffened cylinder based on strength design principles. 


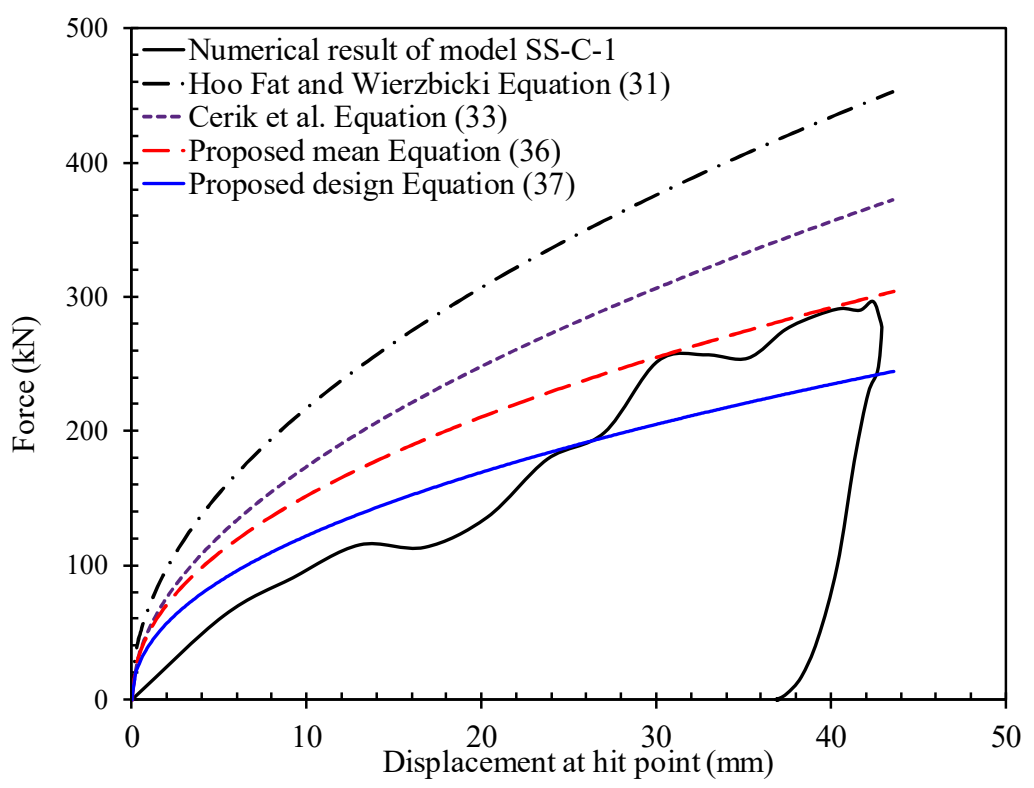

(a)

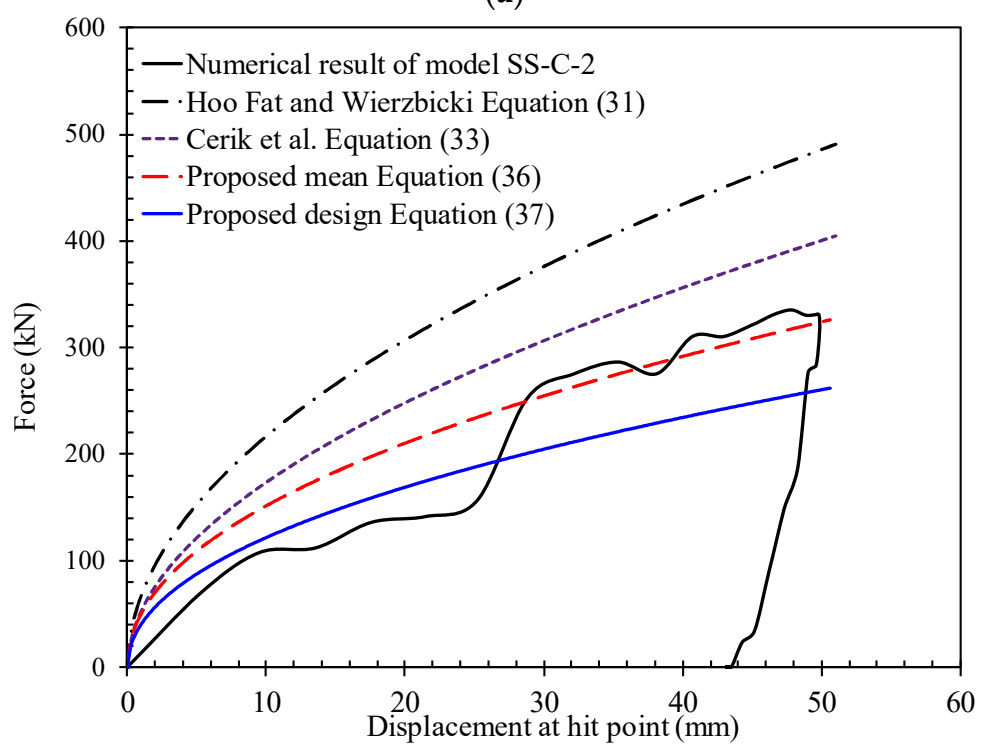

(b)

Figure 29. Comparison of predicted force-displacement relations using proposed formulations with other existing formulations for stringer-stiffener cylinders: (a) Model SS-C-1; (b) Model SS-C-2.

\section{Concluding Remarks}

This study aims to derive empirical formulations for predicting the maximum permanent local dent depth of both ring-stiffened cylinders and stringer-stiffened cylinders under dynamic mass impact. Based on the results of the present study, the following conclusions are drawn:

- For the first time, the simple design equations to predict the maximum permanent local dent depth of a stiffened cylinder subjected to dynamic mass impact were successfully conducted in this study. In these equations, all effect parameters such as impact location factor, impact angle factor, and indenter shape factor were included. The proposed formulations were highly accurate and reliable according to the available test data and other existing formulations. Furthermore, they are convenient to use in the structure's strength and serviceability under risk conditions, during the initial design stage for safety concerns of marine stiffened cylinder structures. 
- The numerical techniques developed in this paper have reasonable accuracy and reliability for predicting the extent of the local denting damage on stiffened cylinder structures under dynamic collisions. Therefore, it can be applied for further parametric investigations of any actual offshore stiffened cylinder structures for developing design guidelines and benchmarking studies on collision problems.

- In case studies, the importance of the strain-rate hardening definition was investigated. The accuracy of numerical results was strongly dependent on the strain-rate hardening definition. Therefore, it is suggested that dynamic material properties should be applied to define plasticity at high strain rates.

- The energy to be dissipated will result in larger deformations for larger impact velocities. When the impact velocities increase larger than $8 \mathrm{~m} / \mathrm{s}$, the increase in stiffness due to the strain rate effect is clear. When the impact velocity increases further, the resistance of the ring-stiffened cylinder against collision decreases due to the tripping of ring-stiffeners near the impact area.

- The extent of local denting damage of the stiffened cylinder was strongly dependent on the impact locations. The permanent dent depth of the unstiffened cylinder approximately doubled in the ring-stiffened cylinder. It was also significantly reduced with each location in the longitudinal direction of the stiffened cylinder. The maximum permanent dent depth almost occurred at the mid-length of the cylinder, and it decreased gradually to the endplate at the boundary conditions because of the membrane stretching of the upper surface of the cylinder shell.

- When considering the effect of the striker header shape, the most severe case is a hemispherical indenter, which resembles highly localized point loading. The resistance of the ring-stiffened cylinder against collision when the load is applied with a hemispherical indenter type was lower than that of the knife-edge and rectangular indenter types by $19 \%$ and $32 \%$, respectively. For the stringer-stiffened cylinder, the resistance of cylinder when the load is applied through a hemispherical indenter is much lower than that of the knife-edge and rectangular indenter types by $26 \%$ and $37 \%$, respectively.

For future works, it is recommended that further studies appear to be necessary to develop the simple design equations to predict the residual strength of dented ring- or/and stringer-stiffened cylinders under hydrostatic pressure, axial compression, as well as longitudinal bending or combinations thereof. Moreover, when the permanent dent depth is known by using the proposed formulation in this study, the reduction factor is quickly predicted. Then, this factor can be multiplied with the ultimate strength of an intact cylinder to obtain the residual strength of the dented ring- or/and stringer-stiffened cylinders.

Author Contributions: Q.T.D. initiated and developed the concepts related to this research work; V.V.H., N.P.-T., T.H.T. and M.T.V. developed the numerical method and validation; M.T.V., V.V.T. and Q.-V.V. proposed improved points and commented on the manuscript; and S.-R.C. proposed the methodology and experimental data. All authors have read and agreed to the published version of the manuscript.

Funding: This research is funded by the Vietnam National Foundation for Science and Technology Development (NAFOSTED) under grant number 107.01-2019.333.

Conflicts of Interest: The authors declare no conflict of interest.

\section{References}

1. Det Norske Veritas. Accident statistics for fixed offshore units on the UK Continental Shelf (1980-2005): Research Report RR566. In HSE Books; HSE: Sudbury, Suffolk, 2007.

2. Cerik, B.C.; Shin, H.; Cho, S.-R. On the resistance of steel ring-stiffened cylinders subjected to low-velocity mass impact. Int. J. Impact Eng. 2015, 84, 108-123. [CrossRef]

3. Ghanbari-Ghazijahani, T.; Jiao, H.; Holloway, D. Experimental study on damaged cylindrical shells under compression. Thin Walled Struct. 2014, 80, 13-21. [CrossRef]

4. Ghanbari-Ghazijahani, T.; Jiao, H.; Holloway, D. Experiments on dented cylindrical shells under peripheral pressure. Thin Walled Struct. 2014, 84, 50-58. [CrossRef] 
5. Ghanbari-Ghazijahani, T.; Jiao, H.; Holloway, D. Experiments on Dented Steel Tubes under Bending. Adv. Struct. Eng. 2015, 18, 1807-1817. [CrossRef]

6. Ghanbari-Ghazijahani, T.; Jiao, H.; Holloway, D. Experiments on locally dented conical shells under axial compression. Steel Compos. Struct. 2015, 19, 1355-1367. [CrossRef]

7. Do, Q.T.; Muttaqie, T.; Shin, H.; Cho, S.-R. Dynamic lateral mass impact on steel stringer-stiffened cylinders. Int. J. Impact Eng. 2018, 116, 105-126. [CrossRef]

8. Do, Q.T.; Muttaqie, T.; Park, S.-H.; Shin, H.; Cho, S.-R. Ultimate strength of intact and dented steel stringer-stiffened cylinders under hydrostatic pressure. Thin Walled Struct. 2018, 132, 442-460. [CrossRef]

9. Do, Q.T.; Muttaqie, T.; Park, S.-H.; Shin, H.; Cho, S.-R. Predicting the collision damage of steel ring-stiffened cylinders and their residual strength under hydrostatic pressure. Ocean Eng. 2018, 169, 326-343. [CrossRef]

10. Wierzbicki, T.; Suh, M. Indentation of tubes under combined loading. Int. J. Mech. Sci. 1988, 30, $229-248$. [CrossRef]

11. Wierzbicki, T.; Fatt, M.S.H. Impact response of a string-on-plastic foundation. Int. J. Impact Eng. 1992, 12, 21-36. [CrossRef]

12. Wierzbicki, T.; Fatt, M.S.H. Damage assessment of cylinders due to impact and explosive loading. Int. J. Impact Eng. 1993, 13, 215-241. [CrossRef]

13. Fatt, M.S.H.; Wierzbicki, T. Denting analysis of ring stiffened cylindrical shells. Int. J. Offshore Polar Eng. 1991, 1, 137-145.

14. Moussouros, M.; Fatt, M.H. Effect of shear on plastic denting of cylinders. Int. J. Mech. Sci. 1995, 37, 355-371. [CrossRef]

15. Jones, N. The credibility of predictions for structural designs subjected to large dynamic loadings causing inelastic behaviour. Int. J. Impact Eng. 2013, 53, 106-114. [CrossRef]

16. Cerik, B.C. Ultimate strength of locally damaged steel stiffened cylinders under axial compression. Thin Walled Struct. 2015, 95, 138-151. [CrossRef]

17. Cho, S.-R.; Muttaqie, T.; Do, Q.T.; Kim, S.; Kim, S.M.; Han, D.-H. Experimental investigations on the failure modes of ring-stiffened cylinders under external hydrostatic pressure. Int. J. Nav. Arch. Ocean Eng. 2018, 10, 711-729. [CrossRef]

18. Cho, S.-R.; Do, Q.T.; Shin, H. Residual strength of damaged ring-stiffened cylinders subjected to external hydrostatic pressure. Mar. Struct. 2017, 56, 186-205. [CrossRef]

19. Cho, S.-R.; Muttaqie, T.; Do, Q.T.; So, H.Y.; Sohn, J.-M. Ultimate strength formulation considering failure mode interactions of ring-stiffened cylinders subjected to hydrostatic pressure. Ocean Eng. 2018, 161, 242-256. [CrossRef]

20. Muttaqie, T.; Do, Q.T.; Prabowo, A.R.; Cho, S.R.; Sohn, J.M. Numerical studies of the failure modes of ring-stiffened cylinders under hydrostatic pressure. Struct. Eng. Mech. 2019, 70, 431-443. [CrossRef]

21. Cho, S.-R.; Muttaqie, T.; Do, Q.T.; Park, S.H.; Kim, S.M.; So, H.Y.; Sohn, J.M. Experimental study on ultimate strength of steel-welded ring-stiffened conical shell under external hydrostatic pressure. Mar. Struct. 2019, 67, 102634. [CrossRef]

22. Prabowo, A.R.; Putranto, T.; Sohn, J.M. Simulation of the Behavior of a Ship Hull under Grounding: Effect of Applied Element Size on Structural Crashworthiness. J. Mar. Sci. Eng. 2019, 7, 270. [CrossRef]

23. Rathinam, N.; Prabu, B. Numerical study on influence of dent parameters on critical buckling pressure of thin cylindrical shell subjected to uniform lateral pressure. Thin Walled Struct. 2015, 88, 1-15. [CrossRef]

24. Cerik, B.C.; Ringsberg, J.W.; Choung, J. Revisiting MARSTRUCT benchmark study on side-shell collision with a combined localized necking and stress-state dependent ductile fracture model. Ocean Eng. 2019, 187, 106173. [CrossRef]

25. Cerik, B.C. Damage assessment of marine grade aluminium alloy-plated structures due to air blast and explosive loads. Thin Walled Struct. 2017, 110, 123-132. [CrossRef]

26. Cerik, B.C.; Lee, K.; Park, S.-J.; Choung, J. Simulation of ship collision and grounding damage using Hosford-Coulomb fracture model for shell elements. Ocean Eng. 2019, 173, 415-432. [CrossRef]

27. Prabowo, A.R.; Bae, D.M.; Sohn, J.M.; Zakki, A.; Cao, B.; Cho, J.H. Effects of the rebounding of a striking ship on structural crashworthiness during ship-ship collision. Thin Walled Struct. 2017, 115, 225-239. [CrossRef]

28. Zhang, S.; Pedersen, P.T. A method for ship collision damage and energy absorption analysis and its validation. Ships Offshore Struct. 2016, 12, S11-S20. [CrossRef] 
29. Liu, B.; Villavicencio, R.; Zhang, S.; Soares, C.G. Assessment of external dynamics and internal mechanics in ship collisions. Ocean Eng. 2017, 141, 326-336. [CrossRef]

30. Hong, L.; Amdahl, J. Crushing resistance of web girders in ship collision and grounding. Mar. Struct. 2008, 21, 374-401. [CrossRef]

31. Storheim, M.; Amdahl, J.; Martens, I. On the accuracy of fracture estimation in collision analysis of ship and offshore structures. Mar. Struct. 2015, 44, 254-287. [CrossRef]

32. Zhang, S.; Villavicencio, R.; Zhu, L.; Pedersen, P.T. Ship collision damage assessment and validation with experiments and numerical simulations. Mar. Struct. 2019, 63, 239-256. [CrossRef]

33. Cowper, G.R.; Symonds, P.S. Strain-hardening and strain-rate effects in the impact loading of cantilever beams. In Technical Report, No. 28; Division of Applied Mathematics, Brown University: Providence, RI, USA, 1957.

34. Lee, H.J.; Kim, S.B. A study on application of material properties in ship collision analysis. In Proceedings of the Annual Autumn Conference of the Social of Naval Architecture of Korea, Jeju, Korea, 5 November 2007.

35. Cho, S.R.; Choi, S.; Son, S. Dynamic material properties of marine steels under impact loadings. In Proceedings of the 2015 World Congress on Advances in Structural Engineering and Mechanics, Incheon, Korea, 21 August 2015.

36. Moulas, D.; Shafiee, M.; Mehmanparast, A. Damage analysis of ship collisions with offshore wind turbine foundations. Ocean Eng. 2017, 143, 149-162. [CrossRef]

37. ABS. Guide for Buckling and Ultimate Strength Assessment for Offshore Structures; American Bureau of Shipping: Houston, TX, USA, 2018.

38. API. Bulletin on Stability Design of Cylindrical Shells. In Policy; American Petroleum Institute: Washington, DC, USA, 2003.

39. BSI. PD 5500: Specification for Unfired Fusion Welded Pressure Vessels; British Standard Institution: London, UK, 2009.

(C) 2020 by the authors. Licensee MDPI, Basel, Switzerland. This article is an open access article distributed under the terms and conditions of the Creative Commons Attribution (CC BY) license (http://creativecommons.org/licenses/by/4.0/). 